\title{
¿Variability of the Stratospheric Quasi-Biennial Oscillation and Its Wave Forcing Simulated in the Beijing Climate Center Atmospheric General Circulation Model
}

\author{
Yixiong Lu, TONGWEN Wu, AND WeIHUA JiE \\ Beijing Climate Center, China Meteorological Administration, Beijing, China \\ ADAM A. SCAIFE \\ Met Office Hadley Centre, and University of Exeter, Exeter, United Kingdom \\ MARTIN B. ANDREWS \\ Met Office Hadley Centre, Exeter, United Kingdom \\ JADWIGA H. RICHTER \\ National Center for Atmospheric Research, Boulder, Colorado
}

(Manuscript received 7 May 2019, in final form 14 October 2019)

\begin{abstract}
It is well known that the stratospheric quasi-biennial oscillation (QBO) is forced by equatorial waves with different horizontal/vertical scales, including Kelvin waves, mixed Rossby-gravity (MRG) waves, inertial gravity waves (GWs), and mesoscale GWs, but the relative contribution of each wave is currently not very clear. Proper representation of these waves is critical to the simulation of the QBO in general circulation models (GCMs). In this study, the vertical resolution in the Beijing Climate Center Atmospheric General Circulation Model (BCC-AGCM) is increased to better represent large-scale waves, and a mesoscale GW parameterization scheme, which is coupled to the convective sources, is implemented to provide unresolved wave forcing of the QBO. Results show that BCC-AGCM can spontaneously generate the QBO with realistic periods, amplitudes, and asymmetric features between westerly and easterly phases. There are significant spatiotemporal variations of parameterized convective GWs, largely contributing to a great degree of variability in the simulated QBO. In the eastward wind shear of the QBO at $20 \mathrm{hPa}$, forcing provided by resolved waves is $0.1-0.2 \mathrm{~m} \mathrm{~s}^{-1}$ day $^{-1}$ and forcing provided by parameterized GWs is $\sim 0.15 \mathrm{~m} \mathrm{~s}^{-1} \mathrm{day}^{-1}$. On the other hand, westward forcings by resolved waves and parameterized GWs are $\sim 0.1$ and $0.4-0.5 \mathrm{~m} \mathrm{~s}^{-1}$ day $^{-1}$, respectively. It is inferred that the eastward forcing of the QBO is provided by both Kelvin waves and mesoscale convective GWs, whereas the westward forcing is largely provided by mesoscale GWs. MRG waves barely contribute to the formation of the QBO in the model.
\end{abstract}

\section{Introduction}

The quasi-biennial oscillation (QBO), one of the most regular modes of atmospheric variability, is characterized by alternating eastward and westward winds descending through the equatorial lower stratosphere. It has been continuously observed since 1953

¿ Denotes content that is immediately available upon publication as open access.

Corresponding author: Yixiong Lu, luyx@cma.gov.cn and features a quasi-biennial period varying between 22 and 34 months (Naujokat 1986; Baldwin et al. 2001). This tropical phenomenon is important for the redistribution of minor trace-gas species involved in ozone chemistry and teleconnections linked with extratropical atmospheric circulation patterns. Observed QBO teleconnections include an apparent QBO modulation of the winter stratospheric polar vortices in both hemispheres (Holton and Tan 1980, 1982; Baldwin et al. 2001; Anstey and Shepherd 2014), the North Atlantic Oscillation (Scaife et al. 2014; Andrews et al. 2019), and tropospheric circulation 
over East Asia (Chen and $\mathrm{Li}$ 2007; Inoue and Takahashi 2013). The QBO is also thought to impact the tropical cyclone activities in the western North Pacific and over the Bay of Bengal region (Ho et al. 2009; Fadnavis et al. 2014), although this relationship is in doubt in the Atlantic basin (Camargo and Sobel 2010). Recently, the QBO is found to have a significant influence on the Madden-Julian oscillation in boreal winter (Yoo and Son 2016; Marshall et al. 2017; Nishimoto and Yoden 2017; Son et al. 2017). Given the high predictability of the stratospheric QBO itself, these teleconnections could possibly be used to improve the skill of seasonal to interannual climate predictions (Thompson et al. 2002; Boer and Hamilton 2008; Scaife et al. 2014).

While the importance of the QBO is recognized, it is still a challenge to simulate the QBO in general circulation models (GCMs). Of the climate models participating in the Chemistry-Climate Model Validation Activity phase 2, only two reported an internally generated QBO, and seven chose to nudge toward observations, while the remainder had no realistic QBO variability. Furthermore, in the recent phase 5 of the Coupled Model Intercomparison Project (CMIP5), only five models spontaneously produced a realistic QBO (Schenzinger et al. 2017; Butchart et al. 2018).

The QBO is a wave-mean flow interaction phenomenon, which is driven by the convectively coupled equatorial waves with different horizontal/vertical scales, including Kelvin waves, mixed Rossby-gravity (MRG) waves, inertial gravity waves (GWs), and mesoscale GWs (Lindzen and Holton 1968; Holton and Lindzen 1972; Takahashi and Boville 1992; Dunkerton 1997). In recent years, a great deal of effort has been made to represent the wave forcing in GCMs properly, so at present several state-of-the-art GCMs are capable of spontaneously generating the QBO (Scaife et al. 2000; Giorgetta et al. 2002, 2006; Kawatani et al. 2005, 2009; Lott and Guez 2013; Richter et al. 2014; Rind et al. 2014; Anstey et al. 2016). Previous studies demonstrate that high vertical resolution is essential for simulating a QBO in GCMs. With a vertical grid spacing of about $500 \mathrm{~m}$ in the upper troposphere and lower stratosphere to represent wave-mean flow interactions between equatorial winds and explicitly resolved waves, a QBO-like oscillation in a GCM was first simulated by Takahashi (1996). Studies using a much higher vertical resolution, for example, $300 \mathrm{~m}$, and increased horizontal resolution also reported the realistic GCM simulation of the QBO (Takahashi 1999; Kawatani et al. 2005, 2009, 2010). Note these studies did not use any nonorographic GW drag parameterization, so the horizontal diffusion and/or cumulus parameterization in the model were tuned to increase the power of waves in the stratosphere. While present model resolution cannot resolve all waves, parameterized convective GWs and/or inertial GWs are commonly included to generate QBO properties close to observations (Scaife et al. 2000, 2002; Xue et al. 2012; Richter et al. 2014; Yu et al. 2017).

Uncertainties, however, in the spectrum of upwardpropagating tropical waves that force the QBO remain a key issue. Particularly, the relative contribution of each wave is still not well understood. Observational estimates of zonal forcing by different types of equatorial waves can significantly differ among state-of-the-art reanalyses, and even the basic zonal flow can vary between reanalyses in regions of the tropical belt where there are few radiosonde observations (Kim and Chun 2015). On the other hand, modeling studies can give more insights into the QBO driving forces. It should be noted that proper representation of wave sources in the model can be crucial to inferring the roles of various equatorial waves in the evolution of QBO. A lack of variability in parameterized wave sources, including the seasonal variation, may cause modeled QBOs to be too regular, that is, to show less intercycle variation than is observed. Including the source-related parameterizations of GW drag results in a greater variability in the duration of each phase of the QBO, which is closer to observations (Kim et al. 2013). Several models participating in the SPARC Quasi-Biennial Oscillation initiative (QBOi) use GW drag that is linked to deep convection or is otherwise stochastic, which should increase the variability of GWs driving the QBO (Butchart et al. 2018). Furthermore, the seasonality of the QBO jets downward progression is modeled more realistically due to the seasonality of physically based GW sources (Schirber et al. 2014).

How can we better represent the GWs generated by tropical convective activity and their effects on the QBO in GCMs? To minimize arbitrary specification of $\mathrm{GW}$ sources, using source-related $\mathrm{GW}$ parameterizations is a valid approach in modeling studies of the QBO wave forcing. This study implements a convective GW parameterization, which is coupled to the deep convection scheme, to examine the wave forcing of the QBO in the Beijing Climate Center Atmospheric General Circulation Model (BCCAGCM). The paper is organized as follows. We describe the model and experiments, analysis methods, and datasets in section 2. Section 3 presents characteristics of the simulated QBO and compares them with observations. Based on a realistic QBO simulation, detailed 
analyses of resolved large-scale waves and parameterized GWs that force the QBO are shown in section 4. A summary and discussions are presented in section 5 .

\section{Model, experiments, and analysis methods}

\section{a. General description of the model}

BCC-AGCM is the atmospheric component of the BCC climate system model (Wu et al. 2008, 2010, 2014). The simulations performed here use a spectral truncation at wavenumber 106 with an associated Gaussian grid of $\sim 1.125^{\circ}$ resolution. The damping time for the maximum wavenumber in the fourth-order horizontal diffusion is $0.7 \mathrm{~h}$ in the present study. The parameterization scheme of deep cumulus convection used in BCCAGCM is based on a bulk cloud model approach, in which the mass change for the adiabatic ascent cloud parcel with altitude is derived from a total energy conservation equation of the whole adiabatic system involving the updraft cloud parcel and the environment (Wu 2012).

The versions of BCC-AGCM participating in CMIP5 have difficulties in simulating the QBO. Here we show that a version of BCC-AGCM, configured with high vertical resolution and convective GW parameterizations, successfully produces a realistic QBO. This version was established during the transition of BCCAGCM from CMIP5 to CMIP6. Both high vertical resolution and parameterized convective GWs were also implemented in the CMIP6 version of BCC-AGCM and benefit a self-generated QBO (Wu et al. 2019). The difference is that the model layer of the CMIP6 version is thicker in the lower stratosphere than that used in this version.

\section{b. Vertical resolution}

The CMIP5 configuration of the BCC-AGCM includes 26 vertical levels with approximately 1100-m vertical spacing throughout the free troposphere and lower stratosphere, with a model top at about $2 \mathrm{hPa}$ (Fig. 1). The vertical coordinate used in the BCCAGCM is the pressure-sigma coordinate. Pure pressure levels which are thought to be more appropriate for middle-atmosphere simulation are set above about $82 \mathrm{hPa}$. There are only seven pure pressure levels to resolve the stratosphere in the CMIP5 configuration and the vertical spacing of the top model layer is about $5.5 \mathrm{~km}$. In this study, we have increased the number of model layers to 68 with a similar model top. The typical vertical resolution of the 68-layer grid is $700 \mathrm{~m}$ from the midtroposphere to the lower stratosphere and better than $1 \mathrm{~km}$ up to the model top. Thirty-five pure pressure levels are used to resolve the stratosphere.

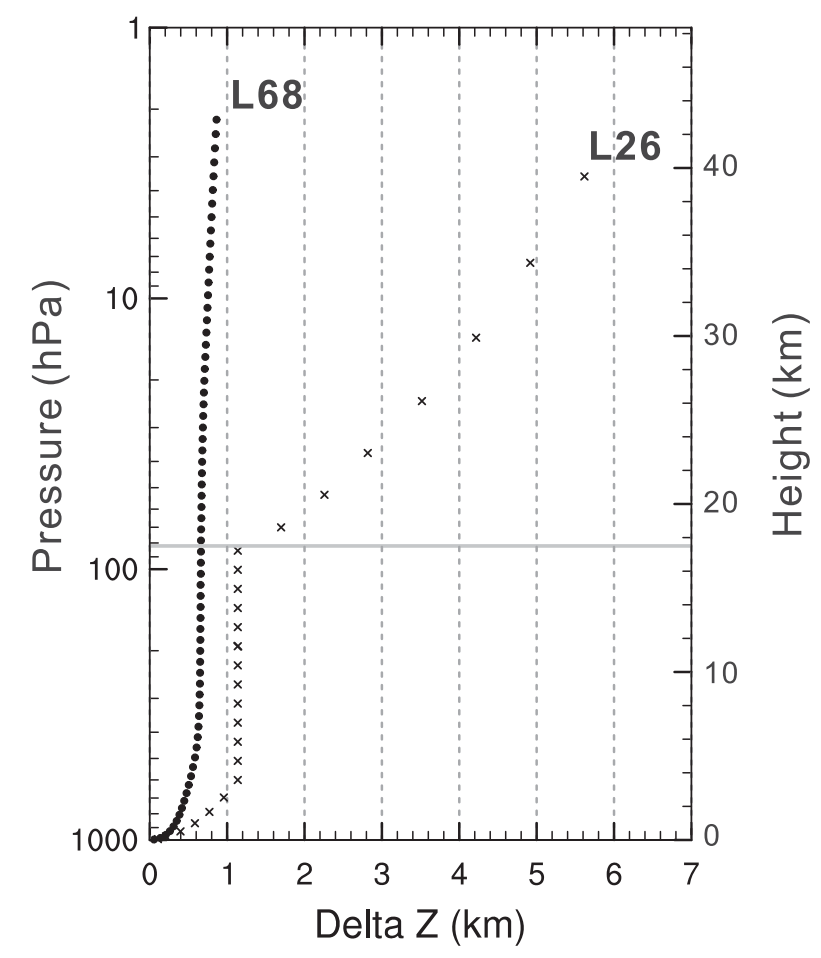

FIG. 1. Profiles of layer thickness vs the height of the model layer for the L26 (crosses) and L68 (dots) grids. Pure pressure levels are above the gray line.

\section{c. Parameterization of convective GWs}

In the original BCC-AGCM, only drag from dissipating GWs originating from flow over orography is considered and parameterized, as in McFarlane (1987). It is clear that nonorographic GWs make a significant contribution to the forcing of the QBO, and so the GW drag generated from convective sources is introduced as in Beres et al. (2004).

The Beres scheme generates a spectrum of gravity waves depending on the convective heating properties and the background wind. To derive the wave spectrum, the following information about the convective region is required: horizontal scale of the heating, heating frequency distribution, heating depth and heating rate, and the mean wind in the heating region. In BCC-AGCM, there is no information available about the horizontal scale of the convective cells and their frequency distribution within the convective region. Following Beres et al. (2004), the horizontal extent of the convective cells is assumed to be $3 \mathrm{~km}$. The vertical heating profile from the deep cumulus parameterization is used to determine the convective heating depth and heating rate. The parameterized convective GWs in the model are the mesoscale waves, with a horizontal wavelength of $100 \mathrm{~km}$. The wave components are specified by 
phase speed from -80 to $80 \mathrm{~m} \mathrm{~s}^{-1}$ with a uniform spacing of $2.5 \mathrm{~m} \mathrm{~s}^{-1}$. These GWs are assumed to have a frequency distribution for wave periods between 10 and $120 \mathrm{~min}$. Waves are launched at the top of the convective heating, from where the propagation routine by Lindzen (1981) calculates for each individual phase speed bin its corresponding breaking level in the atmosphere above.

The key feature of the Beres scheme is relating the momentum flux spectrum to convective heating properties. At a given model time step, the convective GW parameterization is activated at all latitudes where the deep convective heating depth is greater than $2.5 \mathrm{~km}$. The uncertainty in the magnitude of momentum flux determined by this scheme mainly arises from the efficiency parameter. To obtain a reasonable QBO period, this parameter was carefully tuned and set to 0.056 in this study, which is much smaller than the values used in previous studies (Richter et al. 2010, 2014). This may be related to the convection parameterization used in BCC-AGCM.

\section{d. Model configurations and experiments}

Based on model modifications mentioned above, three experiments were carried out. The summary of these experiments is listed in Table 1. The first BCCAGCM run (L26) was configured with 26 model layers and without parameterizations of convective GWs, just as that in CMIP5 configuration. The vertical resolution was increased in the second run (L68). The additional major change in the third run (L68CGW) was the inclusion of the convective gravity wave parameterization. For each experimental setup, we performed a 30-yr Atmospheric Model Intercomparison Project (AMIP)-type simulation with the same prescribed sea surface boundary conditions using the Hadley Centre sea surface temperatures and sea ice concentrations. All the runs also start from identical initial conditions. Historical forcing data are based on observations and mainly include the following: 1) greenhouse gas concentrations with zonal-mean values which are updated monthly; 2) yearly global gridded land use forcing; 3) solar forcing; 4) stratospheric aerosols from volcanoes; 5) anthropogenic aerosol optical properties; and 6) time-varying gridded ozone concentrations. Monthly mean values of model outputs are used as standard temporal resolution for all figures (except for Figs. 7, 8, 12, and 13, which use daily outputs over a 10 -yr period). To evaluate the simulated zonal winds, the reanalysis products of ERA-Interim (Dee et al. 2011) are used. Daily data from the National Oceanic and Atmospheric Administration (NOAA) are used for the space-time spectral analysis of outgoing longwave radiation (OLR; Liebmann and Smith 1996).
TABLE 1. Summary of BCC-AGCM simulations.

\begin{tabular}{lccc}
\hline Experiment & $\begin{array}{c}\text { Horizontal } \\
\text { resolution }\end{array}$ & $\begin{array}{c}\text { Vertical } \\
\text { resolution }(\mathrm{m})\end{array}$ & $\begin{array}{c}\text { Gravity } \\
\text { wave type }\end{array}$ \\
\hline L26 & T106 & 1100 & Orographic \\
L68 & T106 & 700 & $\begin{array}{l}\text { Orographic } \\
\text { L68CGW }\end{array}$ \\
T106 & 700 & $\begin{array}{c}\text { Orographic and } \\
\text { convective }\end{array}$ \\
\hline
\end{tabular}

\section{e. Analysis methods}

In this study, we examine the temporal change of the zonal-mean zonal wind $\bar{u}$ in the framework of the transformed Eulerian-mean (TEM) equations (Andrews et al. 1987), which can be expressed as

$$
\begin{aligned}
\frac{\partial \bar{u}}{\partial t}= & -\left[\frac{1}{a \cos \varphi}(\bar{u} \cos \varphi)_{\varphi}-f\right] \bar{v}^{*} \\
& -\bar{u}_{z} \bar{w}^{*}+\frac{1}{\rho_{0} a \cos \varphi} \nabla \cdot \mathbf{F}+\bar{X},
\end{aligned}
$$

where $a$ is Earth's radius, $\varphi$ is latitude, $f$ is the Coriolis parameter, $z$ is log-pressure height, $\rho_{0}$ is density, the overbar denotes zonal average, and subscripts denote the derivatives with respect to the given variable. The first and second terms on the right-hand side of Eq. (1) represent acceleration associated with the residualmean meridional circulation $\left(\bar{v}^{*}, \bar{w}^{*}\right)$, where

$$
\begin{aligned}
& \bar{v}^{*}=\bar{v}-\frac{1}{\rho_{0}}\left(\rho_{0} \overline{\overline{v^{\prime} \theta^{\prime}}}\right)_{z}, \\
& \bar{w}^{*}=\bar{w}+\frac{1}{a \cos \varphi}\left(\cos \varphi \frac{\overline{v^{\prime} \theta^{\prime}}}{\bar{\theta}_{z}}\right)_{\varphi},
\end{aligned}
$$

where $\theta$ is potential temperature, $\bar{v}$ and $\bar{w}$ are the Eulerian-mean meridional circulation, and prime denotes the departure from zonal mean. The third term on the right-hand side of Eq. (1) represents the divergence of the Eliassen-Palm (E-P) flux

$$
\nabla \cdot \mathbf{F}=\frac{1}{a \cos \varphi}\left[F^{(\varphi)} \cos \varphi\right]_{\varphi}+F_{z}^{(z)},
$$

where

$$
\begin{aligned}
& F^{(\varphi)}=\rho_{0} a \cos \varphi\left(\overline{\frac{v^{\prime} \theta^{\prime}}{\theta_{z}}} \bar{u}_{z}-\overline{v^{\prime} u^{\prime}}\right), \\
& F^{(z)}=\rho_{0} a \cos \varphi\left\{\left[f-\frac{1}{a \cos \varphi}(\bar{u} \cos \varphi)_{\varphi}\right] \overline{\frac{v^{\prime} \theta^{\prime}}{\theta_{z}}}-\overline{w^{\prime} u^{\prime}}\right\},
\end{aligned}
$$


(a) ERA-Interim

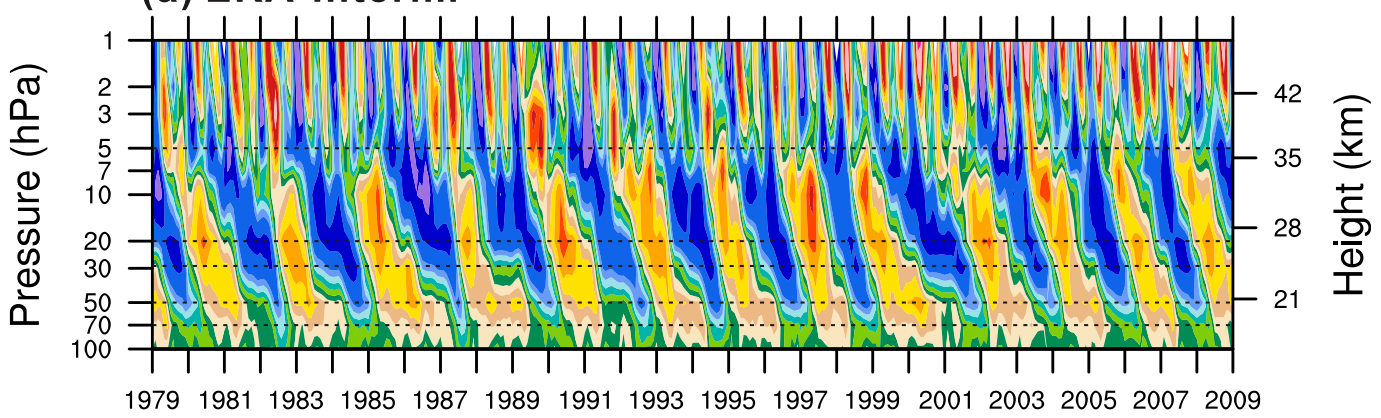

(b) L26

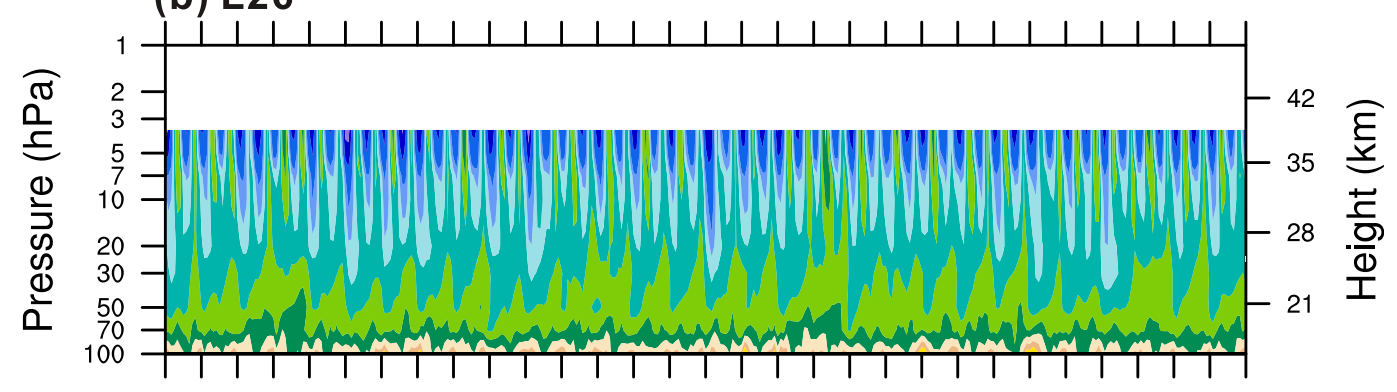

1979198119831985198719891991199319951997199920012003200520072009

(c) L68

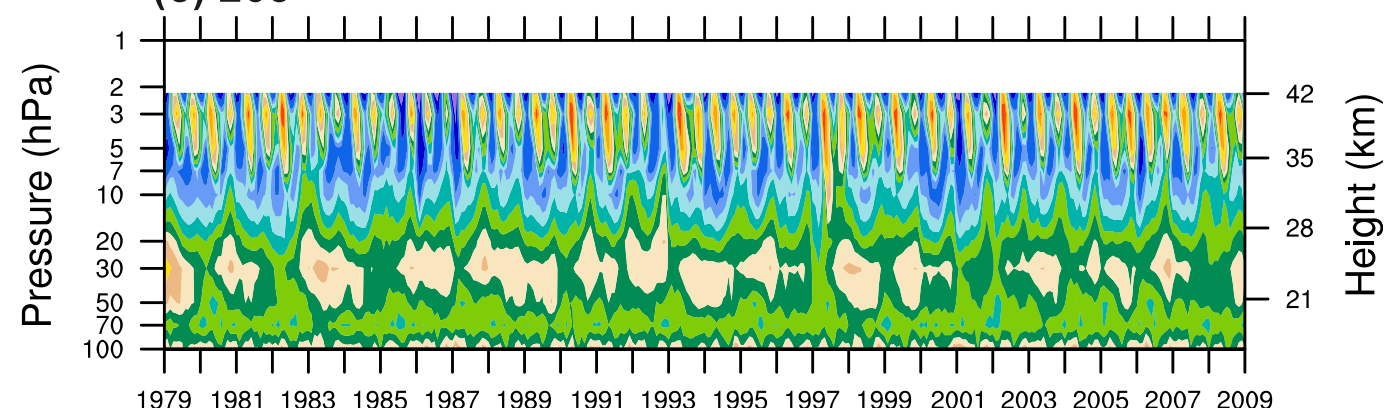

(d) L68CGW
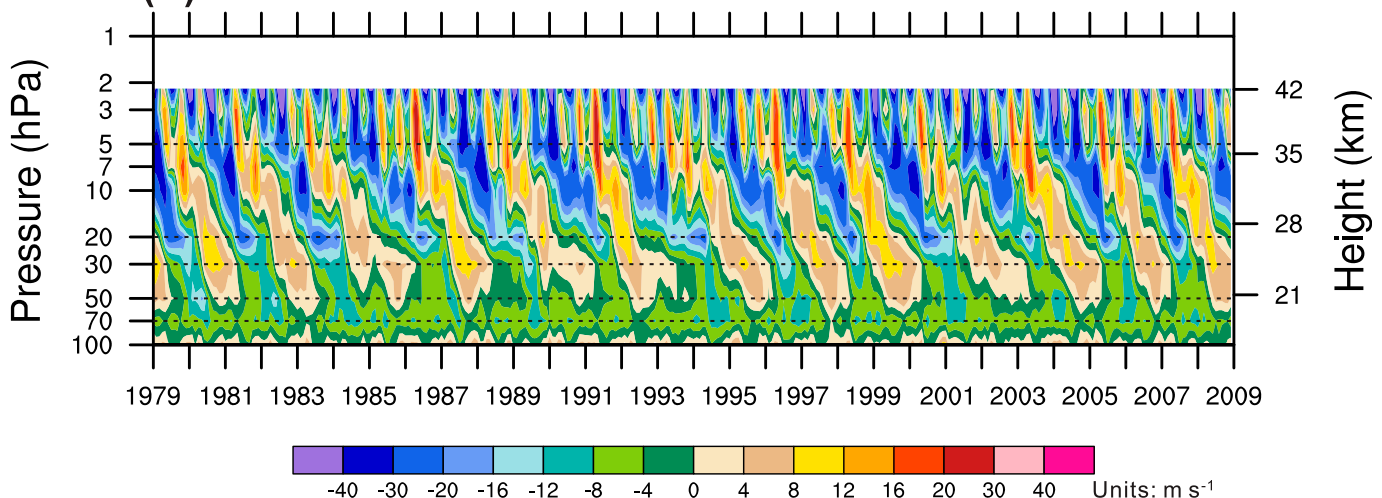

FIG. 2. Time-height cross sections of the monthly tropical zonal winds $\left(\mathrm{m} \mathrm{s}^{-1}\right)$ between $5^{\circ} \mathrm{N}$ and $5^{\circ} \mathrm{S}$ in the lower stratosphere from 1979 to 2008 for (a) ERA-Interim and for (b) L26, (c) L68, and (d) L68CGW simulations. The dashed horizontal lines are for guidance only. 
(a) ERA-Interim

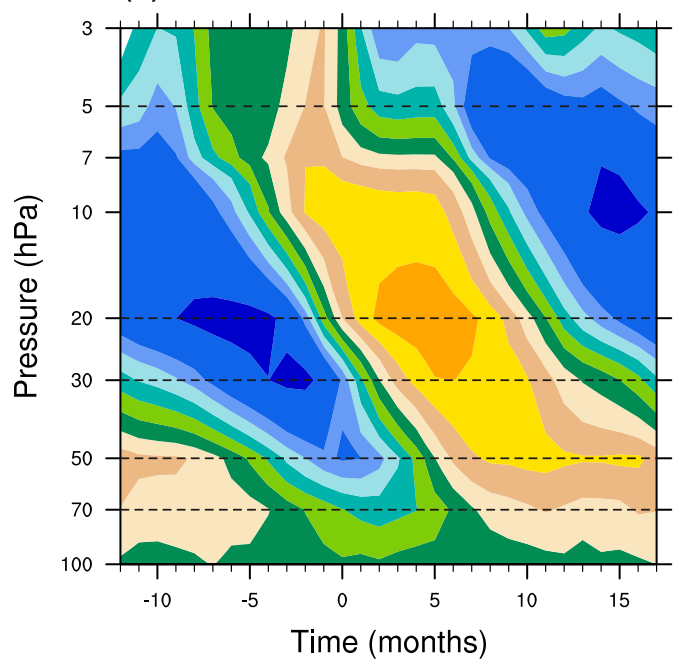

(b) L68CGW
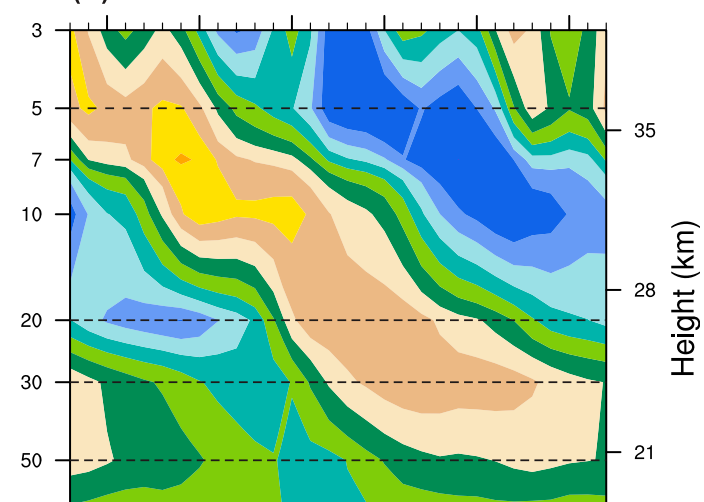

70

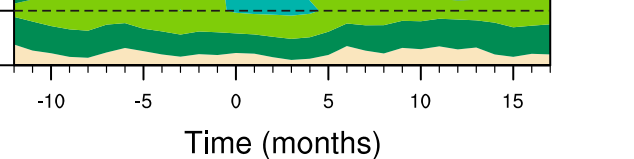

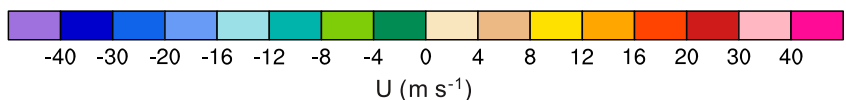

FIG. 3. QBO composites of zonal-mean zonal wind between $5^{\circ} \mathrm{N}$ and $5^{\circ} \mathrm{S}$ for (a) ERA-Interim and (b) L68CGW simulations. Criterion for the composite is the onset of the westerly jet at $20 \mathrm{hPa}$. The dashed horizontal lines are for guidance only.

and $\mathbf{F}=\left[F^{(\varphi)}, F^{(z)}\right]$ is the E-P flux vector. The E-P flux $\mathbf{F}$ and its divergence $\nabla \cdot \mathbf{F}$ are measures of the transport and deposition of zonal momentum and heat by largescale atmospheric waves. The contribution from other processes including mesoscale $\mathrm{GW}$ drag is represented by the $\bar{X}$ term.

It should be noted that eddy terms in the TEM equations are calculated by daily data in this paper, so the E-P flux divergence must be underestimated as resolved waves with periods less than $\sim 2$ days, such as westward inertiagravity (WIG) waves, could not be accounted. Most of convectively coupled equatorial waves, namely, Kelvin, equatorial Rossby (ER), eastward inertia-gravity (EIG), and MRG waves, are at periods more than 2 days (Wheeler and Kiladis 1999; Kiladis et al. 2009).

\section{Characteristics of the simulated QBO}

\section{a. Generation of the $Q B O$}

Figure 2 shows the tropical zonal-mean zonal wind in the lower stratosphere from 1979 to 2008 for ERA-Interim, L26, L68, and L68CGW simulations. Figure 2a shows alternating westerlies and easterlies between 5 and $100 \mathrm{hPa}$ appearing with a period of about 28 months in ERA-Interim. Above $5 \mathrm{hPa}$, a semiannual oscillation (SAO) between easterlies and westerlies can be seen. In the L26 simulation shown in Fig. 2b, however, only a SAO of easterlies can be found.
As mentioned above, the previous 26-layer version of BCC-AGCM participating in CMIP5 does not have the ability to simulate QBO. With increased vertical resolution, a SAO between easterlies and westerlies forms above
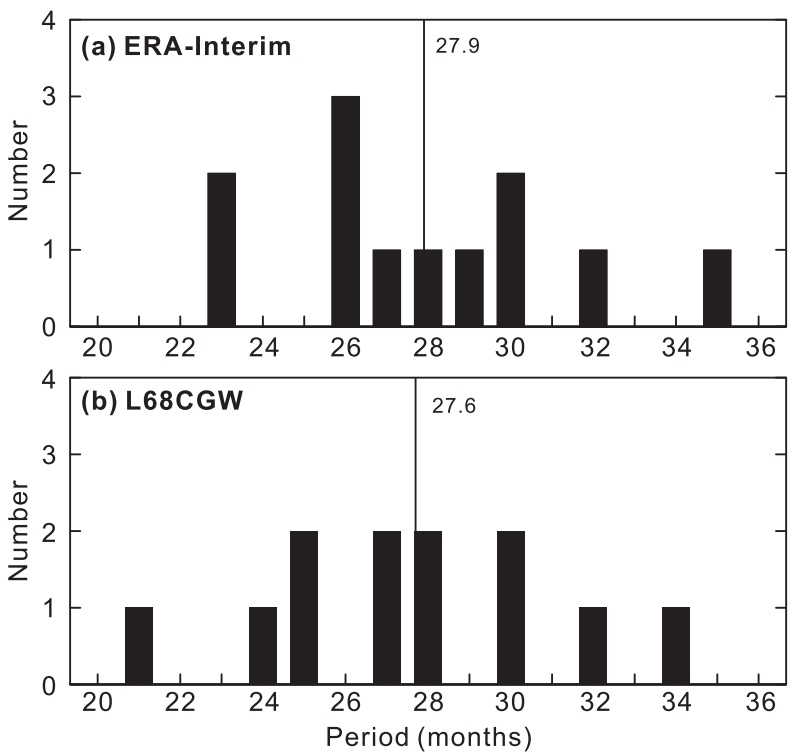

FIG. 4. Histograms of the (a) observed QBO period from ERAInterim and (b) modeled QBO period in L68CGW simulation by BCC-AGCM. The period is taken as the time between easterly-towesterly wind transitions at $20 \mathrm{hPa}$ and vertical lines highlight the mean periods. 


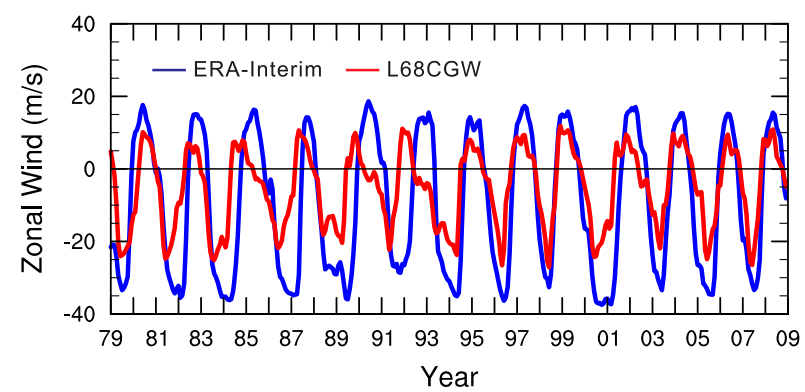

FIG. 5. Time series of the monthly tropical zonal winds $\left(\mathrm{m} \mathrm{s}^{-1}\right)$ between $5^{\circ} \mathrm{N}$ and $5^{\circ} \mathrm{S}$ at $20 \mathrm{hPa}$ from 1979 to 2008 for ERA-Interim (blue line) and the L68CGW simulation (red line).

$5 \mathrm{hPa}$ in the L68 simulation, as shown in Fig. 2c. This may benefit from the high vertical resolution better than $1 \mathrm{~km}$. Additionally, weak westerlies appear from time to time between 20 and $50 \mathrm{hPa}$. As discussed in Richter et al.
(2014), such westerlies are forced by resolved eastwardpropagating equatorial waves. However, the wave forcing is not strong enough to drive a QBO. Figure $2 \mathrm{~d}$ shows that in the L68CGW simulation with both increased vertical resolution and parameterized convective GWs, a clear QBO of the zonal winds is internally generated in BCC-AGCM, confirming that mesoscale GWs make a significant contribution to the forcing of the QBO.

A comparison of QBO composites between ERAInterim and L68CGW is shown in Fig. 3. In the L68CGW simulation, the downward propagation of the QBO phases occurs evidently, but it does not penetrate to sufficiently low altitudes. Simulated easterly jets exceeding $12 \mathrm{~m} \mathrm{~s}^{-1}$ seldom extend downward below $30 \mathrm{hPa}$, whereas they often extend downward below $50 \mathrm{hPa}$, and sometimes below $70 \mathrm{hPa}$ in ERA-Interim. (a) ERA-Interim, WQBO at $20 \mathrm{hPa}$

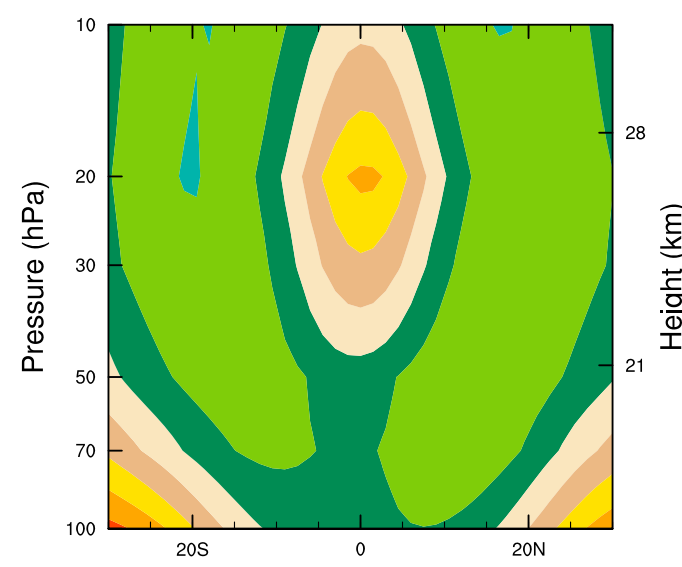

(c) L68CGW, WQBO at $20 \mathrm{hPa}$

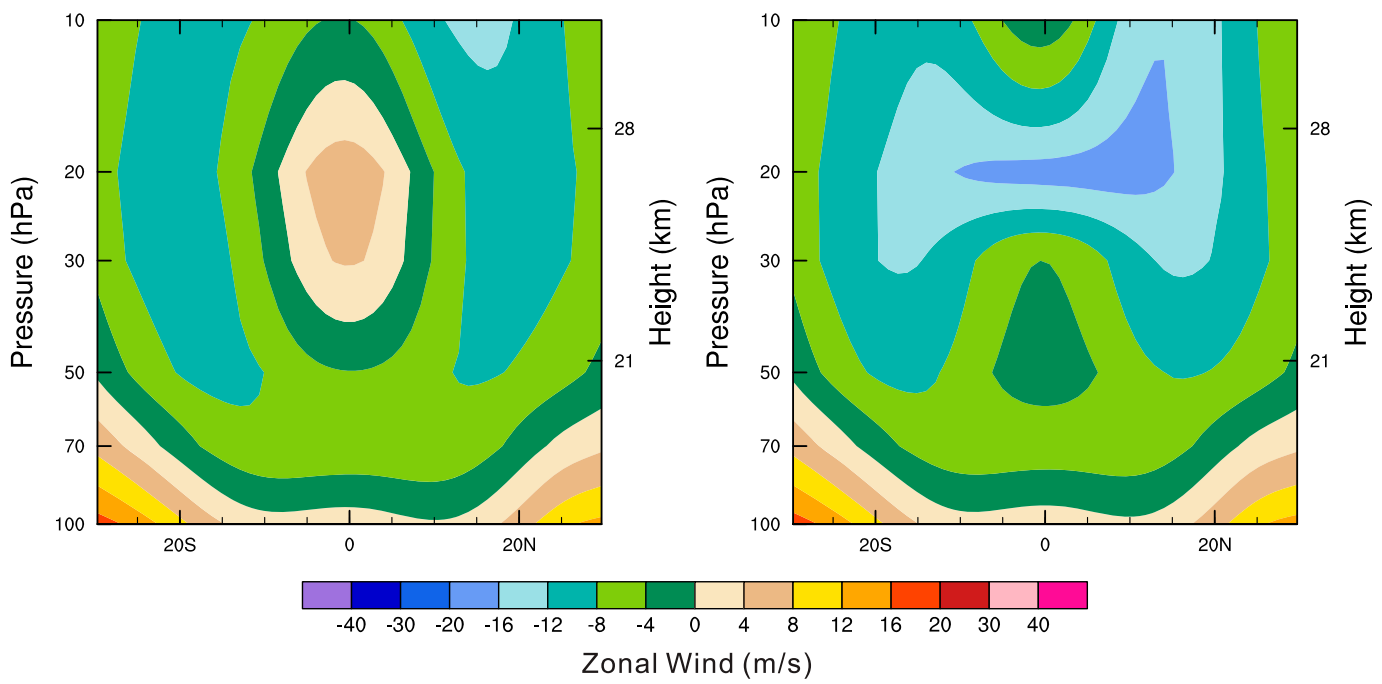

(b) ERA-Interim, EQBO at $20 \mathrm{hPa}$

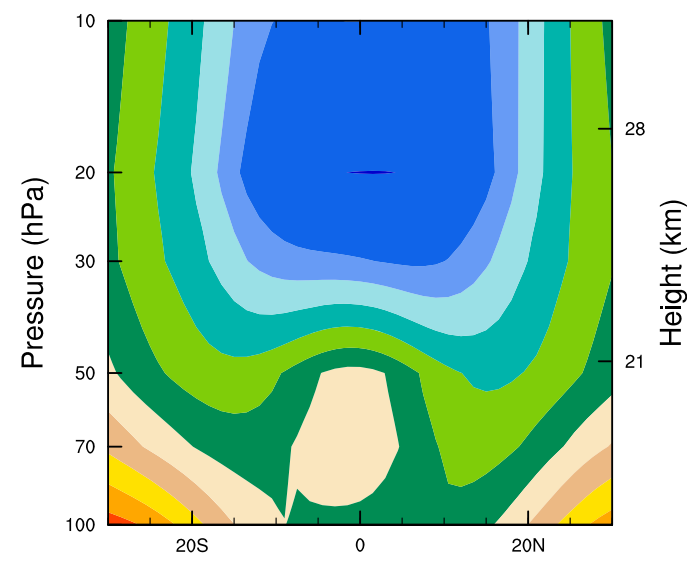

(d) L68CGW, EQBO at $20 \mathrm{hPa}$

FIG. 6. Composite of the zonal-mean zonal wind for the L68CGW experiment when the QBO phase is such that the zonal-mean zonal wind reaches an extreme value at $20 \mathrm{hPa}$. 
ERA-Interim
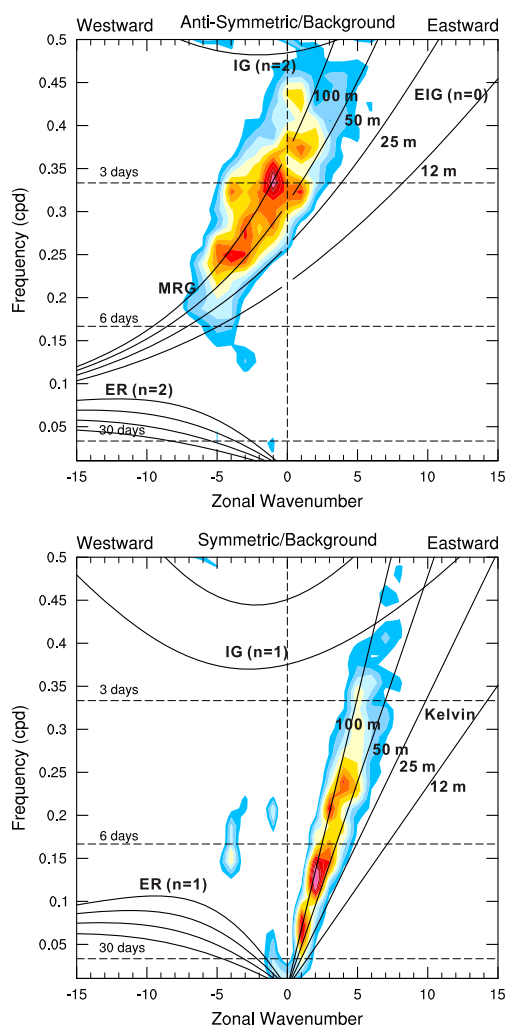

L26
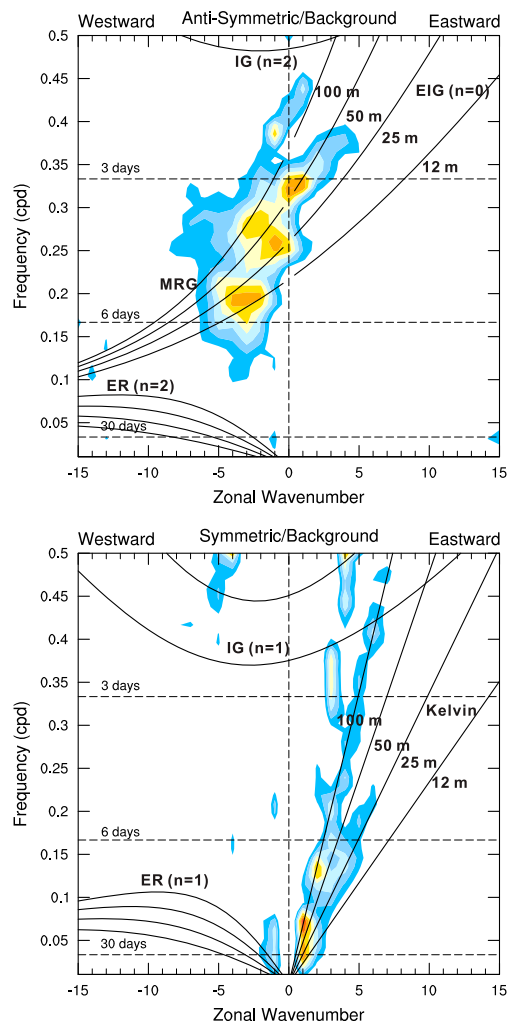

L68CGW
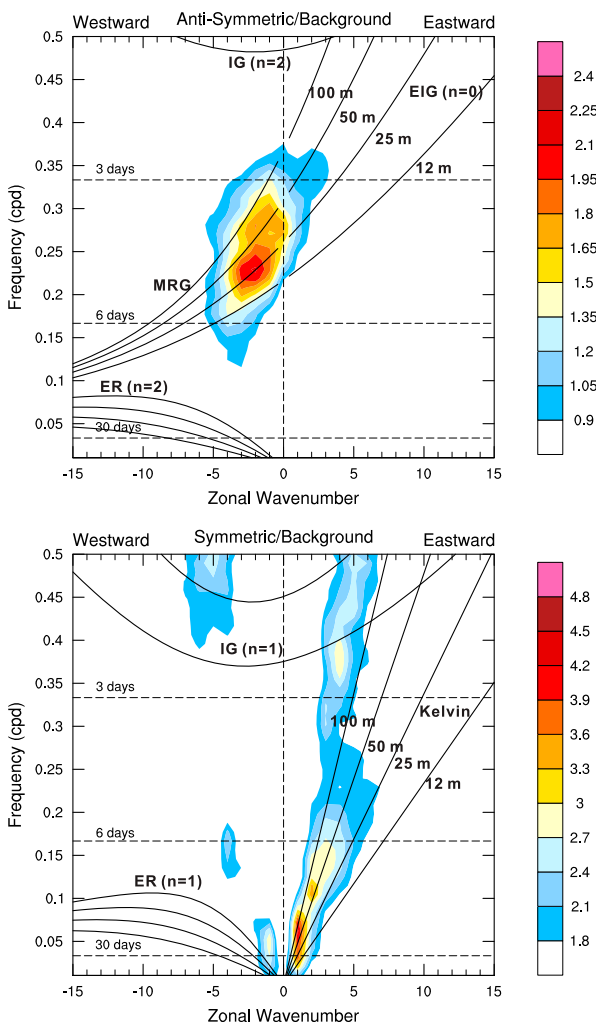

FIG. 7. Wavenumber-frequency spectra divided by the background spectra of (left) ERA-Interim, (middle) L26, and (right) L68CGW, for both (top) antisymmetric and (bottom) symmetric modes, calculated from daily zonal winds at $70 \mathrm{hPa}$ from $10^{\circ} \mathrm{S}$ to $10^{\circ} \mathrm{N}$, using 10 years of data from 1979 to 1988 . Black curves represent analytical dispersion relations of six dry equatorial wave modes for equivalent depths of $12,25,50$, and $100 \mathrm{~m}$.

Also, simulated westerly winds end between 50 and $70 \mathrm{hPa}$ rather than below $70 \mathrm{hPa}$ as in the reanalysis. At higher altitudes, the simulated QBO phases extend to $5 \mathrm{hPa}$ and agree well with ERA-Interim. Though the vertical resolution is increased, it may be still too low to expect a modeled QBO down to at least $70 \mathrm{hPa}$, because the forcing from resolved waves cannot be adequately resolved. It has been argued that relatively fine vertical layering better than $500 \mathrm{~m}$ is required to adequately resolve wave-mean flow interactions in the upper troposphere-lower stratosphere region so that a QBO with proper downward extension can be generated (Geller et al. 2016).

\section{b. The period of the simulated $Q B O$}

The period of the observed QBO is variable. The histograms of the QBO periods in the L68CGW simulation are shown in Fig. 4 and compared to those obtained from the reanalysis dataset. In this study, the QBO period is taken as the time between easterly and westerly wind transitions at $20 \mathrm{hPa}$. The simulation produces about 12 QBO cycles over 30 years with an average period of 27.6 months, very close to the observed mean period of 27.9 months in ERA-Interim. The simulated QBO period ranges from 21 to 34 months, similar to the range of cycles in ERA-Interim which ranges from 23 to 35 months.

In addition to a realistic range, Fig. 4 suggests that the simulated QBO periods follow a continuous distribution as found in the observations. These should be expected given that the parameterized GW launch stress is not held constant in the simulation. Sourcerelated GW sources will increase the variability in the simulated QBO periods.

\section{c. The asymmetry of the simulated $Q B O$}

The asymmetry in amplitude that the easterlies are stronger than the westerlies is a noteworthy feature in the observed QBO. Figure 5 shows time series of the equatorial zonal-mean zonal winds at $20 \mathrm{hPa}$ from ERA-Interim and the L68CGW simulation. The observed easterly winds peak at -30 to $-40 \mathrm{~ms}^{-1}$, whereas westerlies range from 15 to $20 \mathrm{~m} \mathrm{~s}^{-1}$. Compared with ERA-Interim, it shows that the simulated 


\section{OBS}
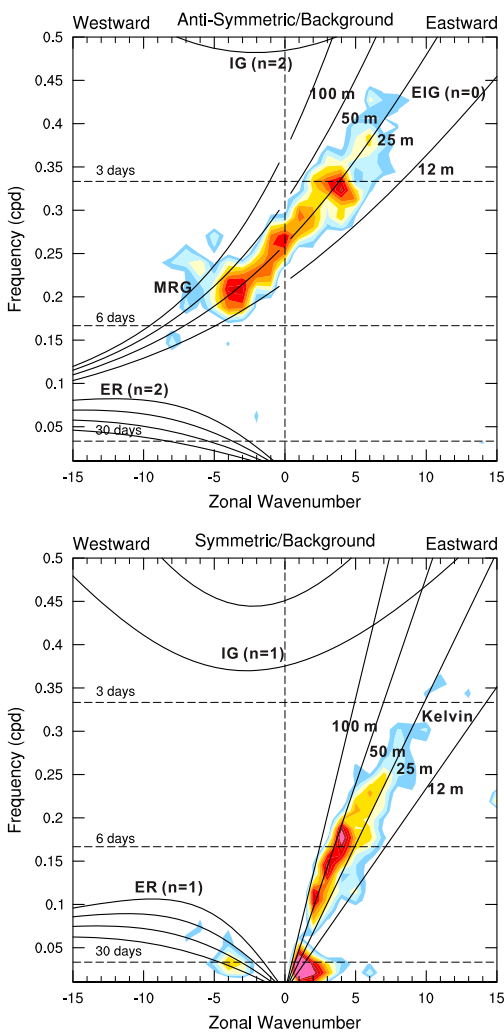

L26
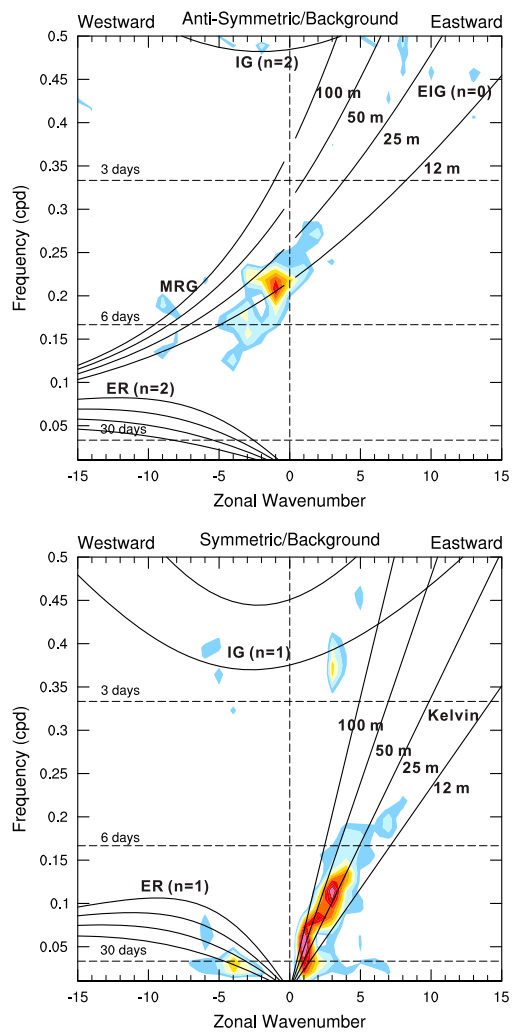

L68CGW
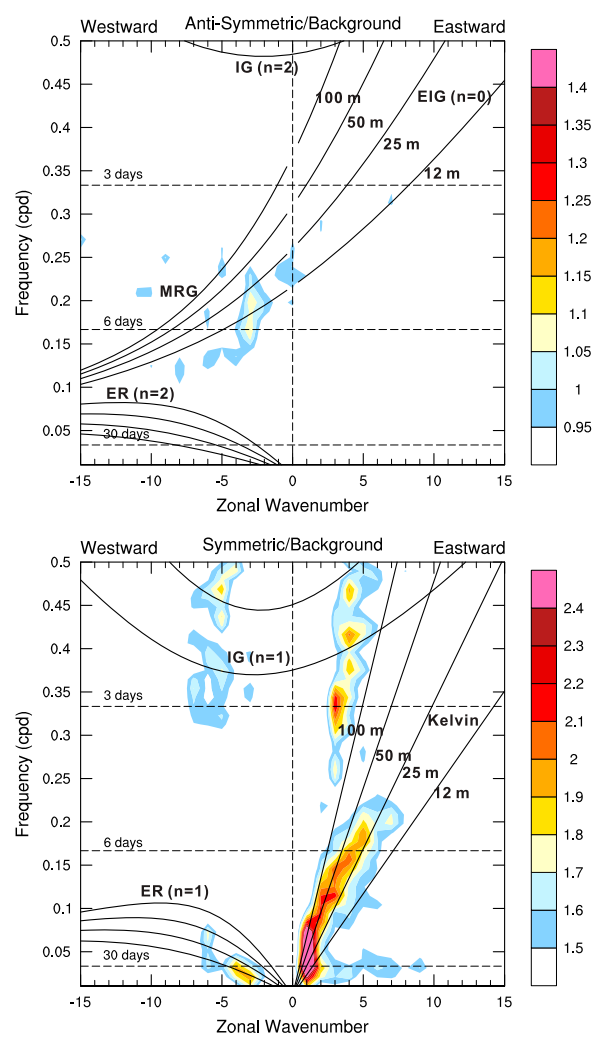

FIG. 8. Wavenumber-frequency spectra divided by the background spectra for OLR from (left) NOAA observations, (middle) L26, and (right) L68CGW, for both (top) antisymmetric and (bottom) symmetric modes, calculated using daily data from 1979 to 1988 between $10^{\circ} \mathrm{S}$ and $10^{\circ} \mathrm{N}$. Black curves represent analytical dispersion relations of six dry equatorial wave modes for equivalent depths of $12,25,50$, and $100 \mathrm{~m}$.

asymmetry agrees well with that found in the observed QBO, although the amplitudes of the QBO cycles in the simulation are generally weaker. The simulated easterlies often exceed $-20 \mathrm{~m} \mathrm{~s}^{-1}$, whereas westerlies show peak winds at $10 \mathrm{~m} \mathrm{~s}^{-1}$.

As well as amplitude, the meridional extent of the two QBO phases is also asymmetric. Figure 6 presents the meridional structure of the composite westerly and easterly QBO phases. In ERA-Interim, the westerly jet in Fig. 6a is narrower than the easterly jet in Fig. 6b. Specifically, the westerly jet is confined to just $10^{\circ}$ of latitude compared to $20^{\circ}$ or more for the easterly phase. As shown in Figs. $6 \mathrm{c}$ and $6 \mathrm{~d}$, this asymmetry in the meridional width of the QBO phases is presented well in the simulation, despite the fact that the modeled jets are weaker than observed. The shapes of simulated easterly (Fig. 6d) are different from those in ERA-Interim (Fig. 6b), around 30 and $15 \mathrm{hPa}$ over the equator. As mentioned above, strong easterly jets seldom propagate downward below $30 \mathrm{hPa}$ in the simulation (Fig. 3b). Also, above $15 \mathrm{hPa}$ the simulated easterlies last shorter than those in ERA-Interim, leading to a weaker composite easterly phase at the higher levels.

\section{Wave forcing of the simulated QBO}

\section{a. Resolved equatorial waves}

Accurate representation of resolved equatorial waves, including Kelvin waves and MRG waves, is crucial to realistic simulation of the QBO in GCMs. To show how the higher vertical resolution can better resolve the QBO-related equatorial waves propagating into the lower stratosphere in our model, the space-time analysis outlined in Wheeler and Kiladis (1999) was performed on the daily $70 \mathrm{hPa}$ zonal winds using 10 years of data from ERA-Interim, L26 and L68CGW simulations. Figure 7 presents the power spectra divided by the background spectra to examine the representation of equatorial wave peaks. The background spectra were calculated individually for the L26 and L68CGW and differ insignificantly between the two simulations. The analytical equatorial wave modes are indicated by dispersion curves 
(a) January GW spectra

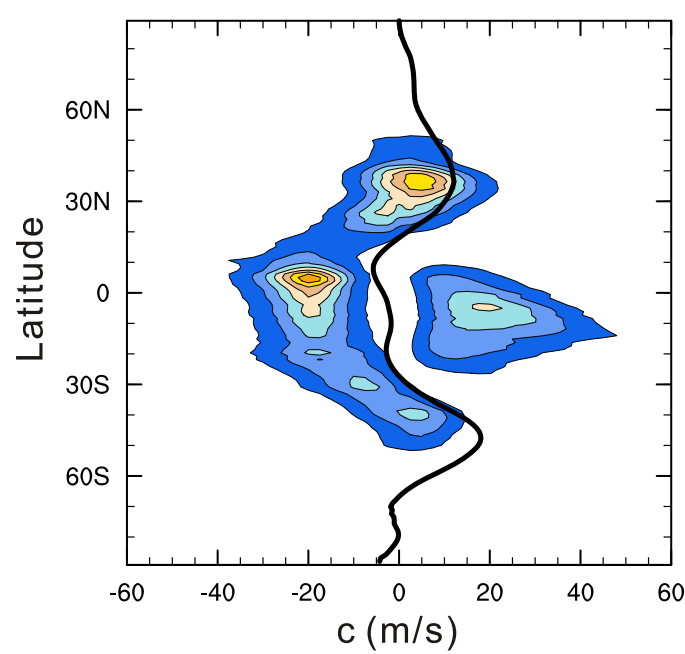

(b) July GW spectra

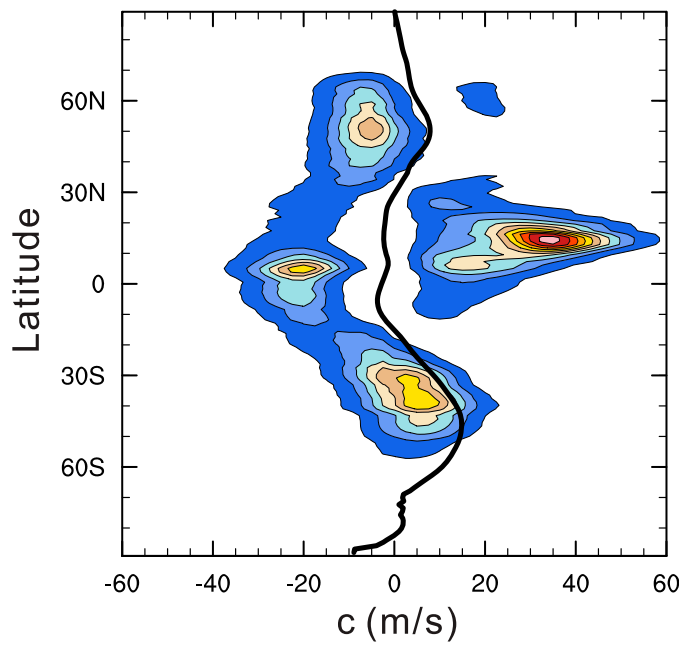

\begin{tabular}{|lllllllllllllll}
\hline & & & & & & & & & & & & & & \\
2 & 4 & 6 & 8 & 10 & 12 & 14 & 16 & 18 & 20 & 22 & $\left(10^{-5} \mathrm{~Pa}\right)$
\end{tabular}

FIG. 9. Monthly mean east-west momentum flux phase speed spectra $\left(10^{-5} \mathrm{~Pa}\right)$ at $100 \mathrm{hPa}$ from the parameterized convective GW source for (a) January and (b) July in the L68CGW simulation. The solid line depicts the zonal-mean wind at $700 \mathrm{hPa}$, the basis for the Doppler shift of the spectrum.

derived from the shallow-water theory. In ERA-Interim (Fig. 7, left), there is power evident in regions of the spectra associated with Kelvin and MRG waves. L26 can represent Kelvin and MRG waves in the lower stratosphere, but the associated power is weaker (Fig. 7, middle). Compared to L26, L68CGW exhibits more power in both the antisymmetric MRG spectrum and the symmetric Kelvin spectrum, closer to ERA-Interim (Fig. 7, right). The increase in MRG power occurs at small, westward-propagating wavenumbers, with periods from 3 to 5 days. The symmetric component enhancements are eastward-propagating Kelvin waves at periods between a few days and more than 20 days.

There may be several factors leading to a better representation of Kelvin and MRG waves in the lower stratosphere in L68CGW. It is shown in Fig. 1 that the model's vertical resolutions in the troposphere are better in L68CGW $(\sim 700 \mathrm{~m})$ than in L26 $(\sim 1100 \mathrm{~m})$. Convective heating may differ between L68CGW and L26 due to increased vertical resolution, resulting in a change in wave generation. Figure 8 shows the wavenumber-frequency spectra for OLR to investigate the influence of wave generation. In the areas corresponding to the dispersion curves, clear signals of MRG waves are present in the antisymmetric component, whereas Kelvin waves are obvious in the symmetric component in the observational data (Fig. 8, left). By comparing the spectra in
L26 (Fig. 8, middle) and L68CGW (Fig. 8, right), it is found that the spectral power reduces in the antisymmetric MRG waves and enhances in the symmetric Kelvin waves, respectively, in the L68CGW with higher vertical resolution in the troposphere. This suggests that the improved Kelvin waves in the lower stratosphere are at least partly due to the wave generation intensification. On the other hand, the enhanced MRG waves in the lower stratosphere cannot be connected to the weakened wave generation. The background zonal wind will affect the resolved waves. It is found in Fig. 2 that the zonal-mean zonal winds at $70 \mathrm{hPa}$ are similar in the two simulations, although a bit more easterly in L68CGW. A possible reason for the increased power of MRG waves in the lower stratosphere is that the wave propagation is improved when the model's vertical resolution is increased.

\section{b. Variability in parameterized convective $G W s$}

It is clear that mesoscale GWs make a significant contribution to the forcing of the QBO, and if the GWs are not resolved, then their effects need to be parameterized for the simulation of the QBO. The variability in the parameterization of the convective GW source largely determines the characteristics of the simulated QBO.

To assess the variability in the parameterized GW source, we first examine the momentum flux phase 


\section{(a) Westward, JAN}

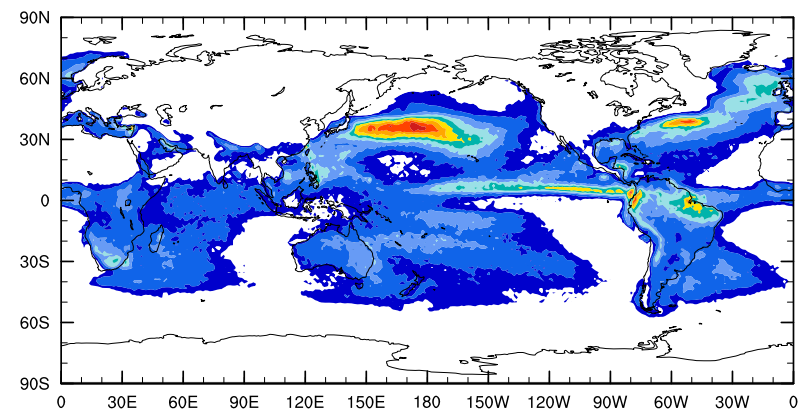

(c) Westward, JUL

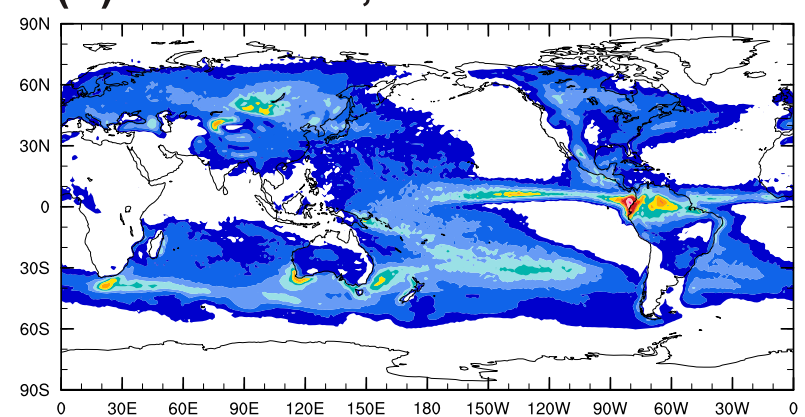

(b) Eastward, JAN

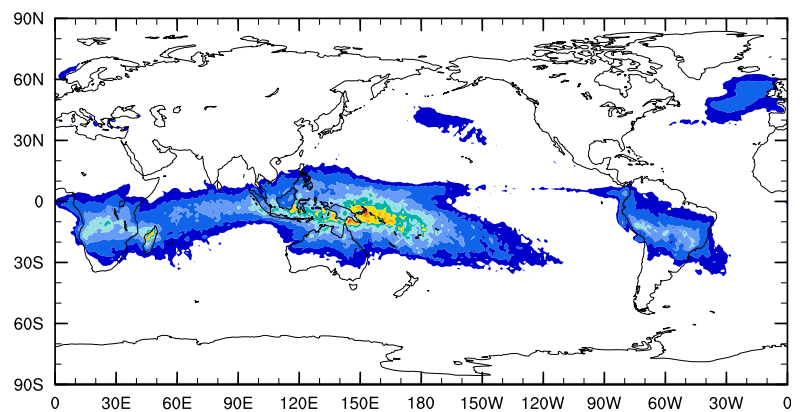

(d) Eastward, JUL

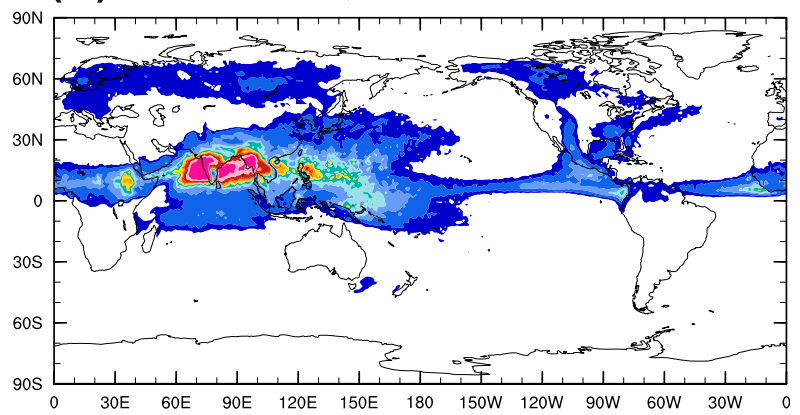

\section{$\begin{array}{llllllllllll}0.25 & 0.5 & 1.0 & 1.5 & 2.0 & 2.5 & 3.0 & 3.5 & 4.0 & 6.0 & 8.0 & \mathrm{mPa}\end{array}$}

FIG. 10. Spatial distributions of (a),(c) westward and (b),(d) eastward GW momentum fluxes $\left(10^{-3} \mathrm{~Pa}\right)$ at $100 \mathrm{hPa}$ from the L68CGW simulation in (top) January and (bottom) July.

speed spectra. Recall that the shape of the momentum flux phase speed spectra is determined by the convective heating depth and the tropospheric wind. Figure 9 shows the east-west momentum flux phase speed spectra at $100 \mathrm{hPa}$ for January and July from the convective GW source parameterization. The dominant GW phase speed and the breadth of the phase speed spectrum vary with time and latitude due to variations in the heating depth and the tropospheric wind. In the tropics, the east-west momentum flux phase speed spectra for convective GWs have two distinct peaks. In January (Fig. 9a), the dominant phase speed of westward- (eastward-) propagating waves is $-20 \mathrm{~m} \mathrm{~s}^{-1}\left(20 \mathrm{~m} \mathrm{~s}^{-1}\right)$, with the momentum flux for westward-propagating waves being $60 \%$ larger than that for eastward ones. In July (Fig. 9b), the spectrum is different from that in January. The dominant phase speed of eastwardpropagating waves increases to about $30 \mathrm{~m} \mathrm{~s}^{-1}$ while the magnitude of momentum flux is about two times as large as it is for westward-propagating waves. Outside of the tropics, the properties of GWs generated by extratropical convection differ considerably from those generated in the tropics. At higher latitudes, the momentum flux spectrum has only one dominant phase speed.

The spatial variability of convective GW momentum flux at $100 \mathrm{hPa}$ is illustrated in Fig. 10, in which the spatial pattern of the momentum flux is highly correlated with that of convective sources. The largest contribution to westward momentum flux in January is in regions of midlatitude storm tracks on the northwest Pacific and Atlantic Oceans and tropical storms over equatorial eastern Pacific, with maxima of 3-6 $\mathrm{mPa}$ (Fig. 10a). In the eastward momentum flux, the primary peak is located in the Maritime Continent regions (Fig. 10b). The spatial distributions of the momentum fluxes entering the stratosphere in January presented here are generally similar to the study of Kim et al. (2013), who implemented a convective GW source parameterization in the Met Office Unified Model and found more spatial variations in the GW momentum flux compared to that from empirically prescribed source parameterizations. In July, the spatial distributions of GW momentum fluxes are different due to seasonal changes in convective activities. The primary peak of the westward momentum flux associated with storm track changes to the Southern 
(a) Convective Westward MF

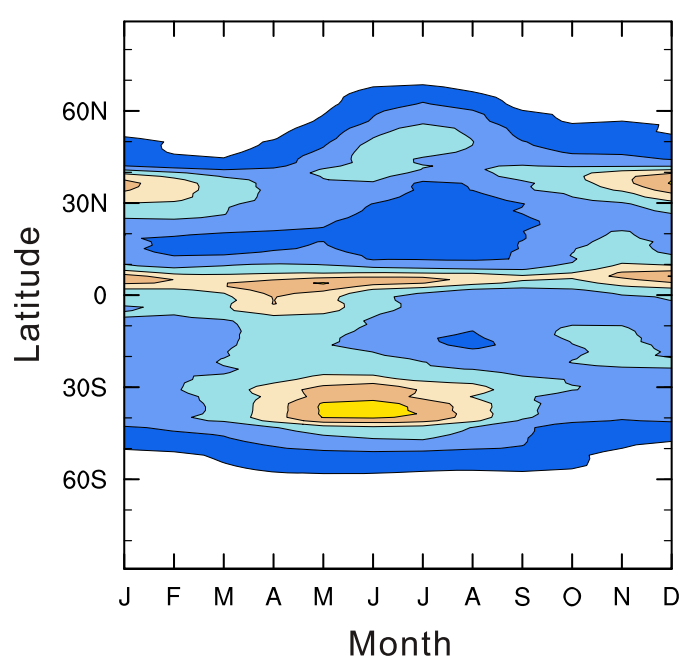

(b) Convective Eastward MF

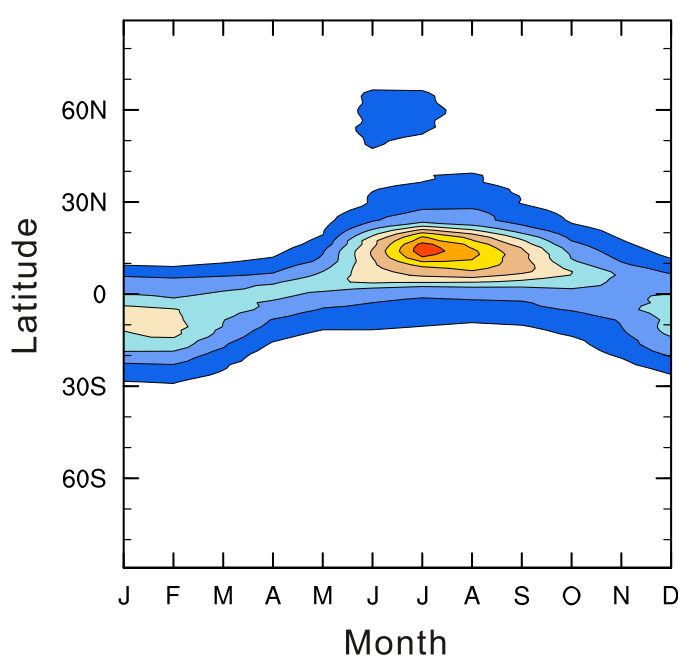

$\begin{array}{lllllllll}0.2 & 0.4 & 0.6 & 0.8 & 1.0 & 1.2 & 1.4 & 1.6 & \mathrm{mPa}\end{array}$

FIG. 11. Total (a) westward and (b) eastward momentum fluxes $\left(10^{-3} \mathrm{~Pa}\right)$ at $100 \mathrm{hPa}$ from convective GWs as a function of latitude and time of year in L68CGW.

Hemisphere midlatitudes (Fig. 10c), while the local maxima of the eastward momentum flux shifts to Asian summer monsoon regions (Fig. 10d). Furthermore, significant GW momentum fluxes are shown over the Northern Hemisphere continents in July, both in westward and eastward momentum fluxes. Figure 10 also shows more eastward (westward) GW momentum fluxes in the Eastern (Western) Hemisphere tropics, which is strongly influenced by the Walker circulation. The zonal wind associated with the Walker circulation is easterly (westerly) in the Eastern (Western) Hemisphere and allows most of the eastward (westward) GWs to propagate from the upper troposphere to the stratosphere, whereas the westward (eastward) GWs are prevented from entering the stratosphere. Similar results have been found by Kawatani et al. $(2009,2010)$.

The seasonal cycle of the convective GW momentum flux at $100 \mathrm{hPa}$ is illustrated in Fig. 11. Evident westward momentum flux near $10^{\circ} \mathrm{N}$ is present in all seasons, which could be related with the convection in the intertropical convergence zone (ITCZ); meanwhile, the primary westward momentum flux is in the winter hemisphere, where the strong subtropical westerly jet is located. The maximum eastward momentum flux appears in the summer hemisphere, due to the fact that the convective activity in the tropics also has a maximum near $10^{\circ}$ in the summer hemisphere, which largely modulates the amplitude of the momentum flux. Additionally, the eastward convective
GWs are hardly filtered by the easterlies in the summer near $10^{\circ} \mathrm{N}$.

\section{c. Relative contributions of wave forcing}

The QBO results from the net effect of various processes acting on the zonal momentum, the most important being the wave-mean flow interaction and the residual-mean meridional circulation. In this study, the wave-mean flow interaction involves both the resolved dynamical effects including waves up to the truncation limit at wavenumber 106 in the L68CGW experiment, and the parameterized effects of the interaction of the unresolved GWs with the resolved wind. The resolved wave-mean flow interaction is diagnosed as the divergence of the E-P flux, while the parameterized GW drag is directly accessible within the GCM integration.

The relative roles of waves in driving the QBO depend on height (Kawatani et al. 2010). Figure 12a shows that at $10 \mathrm{hPa}$, both the eastward and westward forcing by resolved waves can reach $0.2 \mathrm{~m} \mathrm{~s}^{-1} \mathrm{day}^{-1}$. The forcing by parameterized convective GWs is comparable to that by resolved waves. At $20 \mathrm{hPa}$ (Fig. 12b), the eastward forcing by resolved waves is about 0.1$0.2 \mathrm{~m} \mathrm{~s}^{-1} \mathrm{day}^{-1}$ at peaks and the westward forcing reduces to $\sim 0.1 \mathrm{~m} \mathrm{~s}^{-1} \mathrm{day}^{-1}$. On the other hand, the eastward forcing by parameterized convective GWs is $\sim 0.15 \mathrm{~m} \mathrm{~s}^{-1}$ day $^{-1}$, which is comparable to that by resolved waves, and the westward forcing by parameterized GWs maximizes between $0.4-0.5 \mathrm{~m} \mathrm{~s}^{-1} \mathrm{day}^{-1}$, which is significantly stronger than that by resolved 
(a) $10 \mathrm{hPa}$

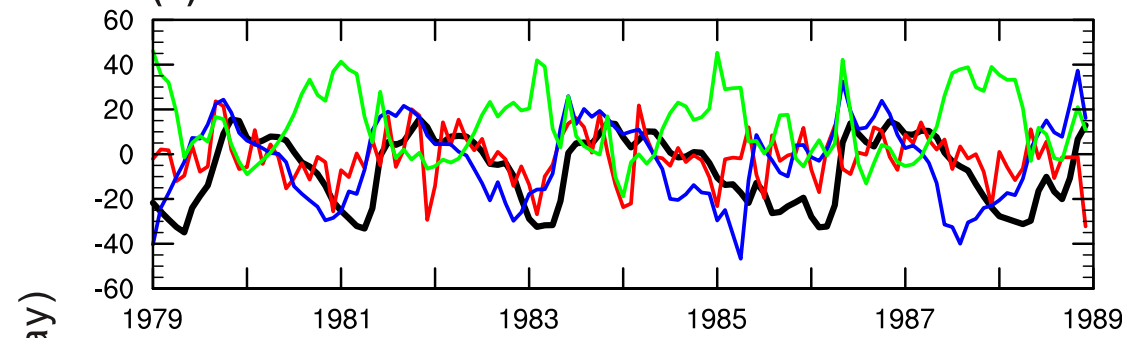

(b) $20 \mathrm{hPa}$

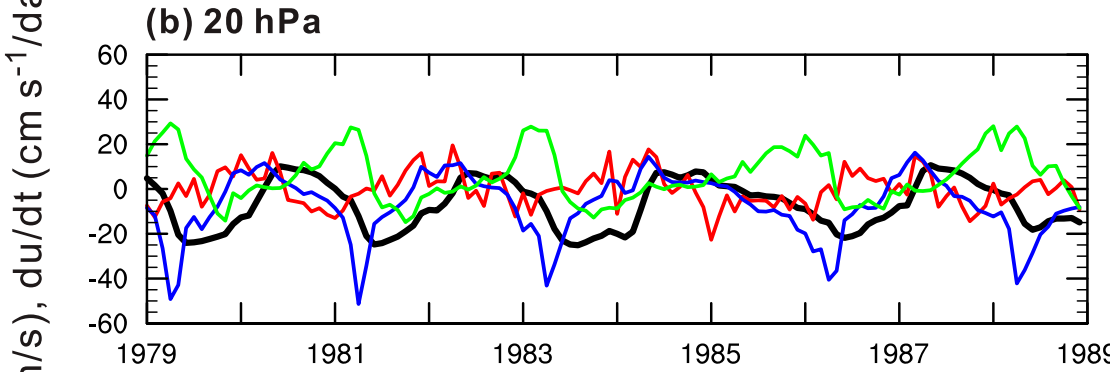

(c) $50 \mathrm{hPa}$

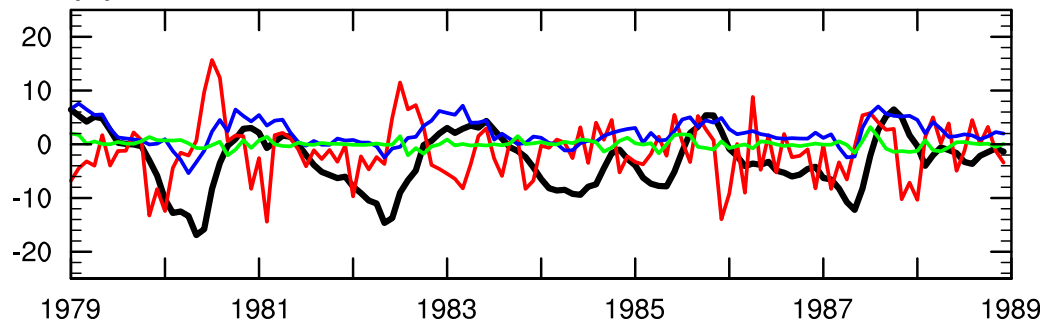

FIG. 12. Wave forcing from the resolved waves (red line), the residual-mean meridional circulation (green line), and parameterized mesoscale convective GWs (blue line), together with zonal-mean zonal wind (black line) averaged between $5^{\circ} \mathrm{N}$ and $5^{\circ} \mathrm{S}$ at (a) 10, (b) 20, and (c) $50 \mathrm{hPa}$ from 1979 to 1988 in L68CGW.

waves. Both the resolved and parameterized wave forcing peak around the westerly wind shear or easterly wind shear, signifying their role in reversing the wind. At $50 \mathrm{hPa}$ (Fig. 12c), neither resolved waves nor parameterized CGWs provides significant forcing, resulting in transitions of weak westerly and easterly winds. It should be noted that the forcing due to CGWs is much smaller than resolved waves at $50 \mathrm{hPa}$. There are some assumptions for the CGW parameterizations used in this study, such as horizontal wavelength of $100 \mathrm{~km}$ and frequency distribution for wave periods between 10 and $120 \mathrm{~min}$. It is found in Fig. 9 that the phase speeds of CGWs momentum have large values around -20 and $20-50 \mathrm{~m} \mathrm{~s}^{-1}$ while they are very small between -10 and $10 \mathrm{~m} \mathrm{~s}^{-1}$, possibly due to the assumptions. In this case, the CGWs did not play major roles in driving the QBO in the lower stratosphere where the QBO amplitude is much smaller.

The residual-mean meridional circulation, especially vertical advection of momentum from upwelling present in the tropical stratosphere, tends to oppose the wind transitions of the QBO. It is found in Figs. 12a and $12 \mathrm{~b}$ that the acceleration due to the residual-mean meridional circulation is largest during the transition to westward winds (up to $0.4 \mathrm{~m} \mathrm{~s}^{-1} \mathrm{day}^{-1}$ at $10 \mathrm{hPa}$ and $\sim 0.3 \mathrm{~m} \mathrm{~s}^{-1} \mathrm{day}^{-1}$ at $20 \mathrm{hPa}$ ), and always acts to offset the strong westward forcing by convective GWs. During the transition to eastward winds, however, the resulting acceleration is insignificant and only weakly offsets the eastward forcing. At lower altitude of $50 \mathrm{hPa}$ (Fig. 12c), the QBO-related residual circulation disappears.

Figure 13 shows the time-height cross sections of the momentum forcing obtained from resolved equatorial waves consisting of Kelvin waves and MRG waves and parameterized convective GWs averaged over a latitude band of $5^{\circ} \mathrm{N}-5^{\circ} \mathrm{S}$ from 1979 to 1988 in L68CGW. Eastward forcing is provided by both resolved waves (Fig. 13a) and parameterized GWs (Fig. 13d). However, the largest values of the parameterized drag are primarily contained above $30 \mathrm{hPa}$, whereas drag from resolved waves extends from 10 to $50 \mathrm{hPa}$. Figure $13 \mathrm{~b}$ shows that the resolved eastward forcing 
(a) Forcing by all resolved waves

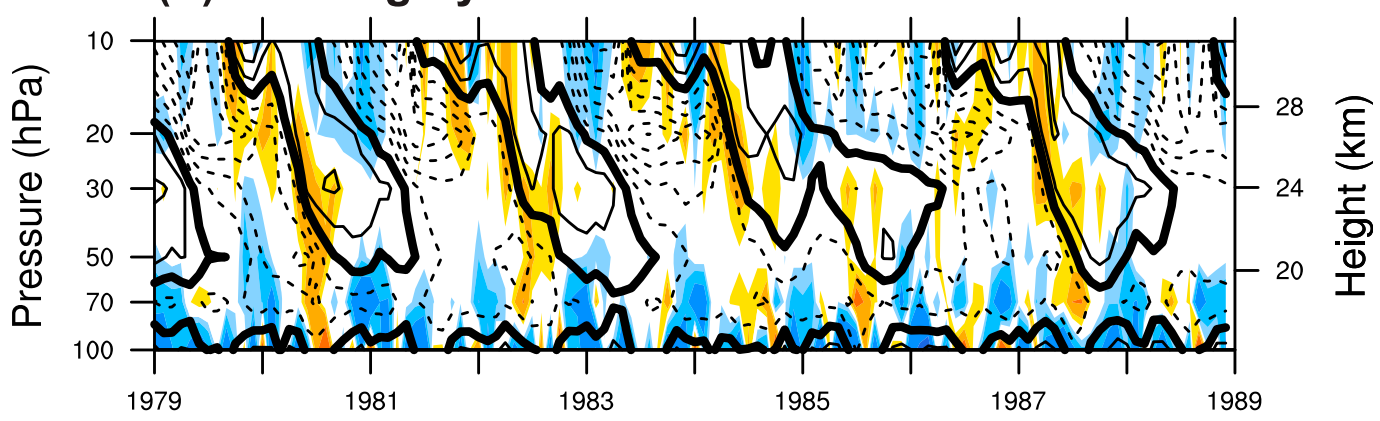

(b) Forcing by Kelvin waves

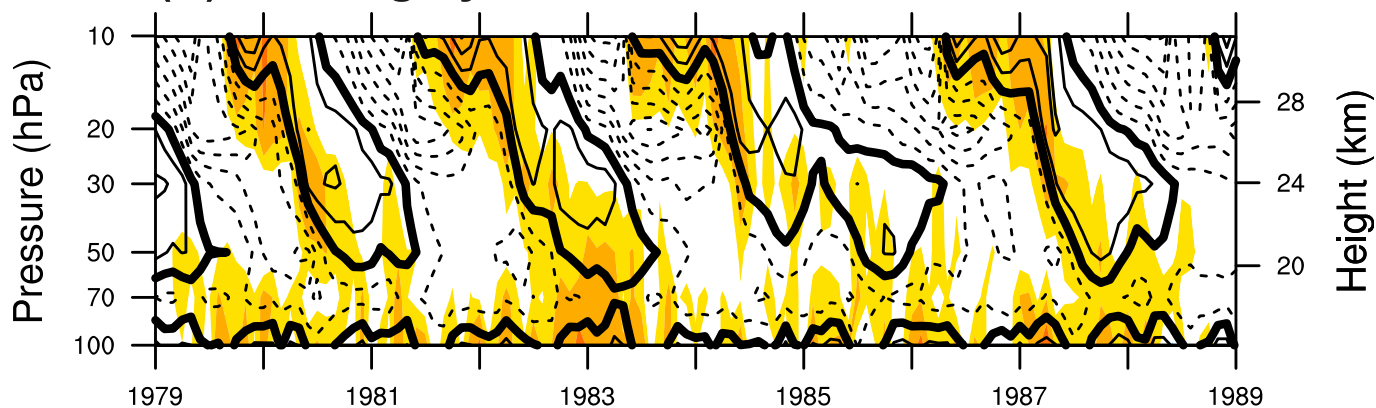

(c) Forcing by MRG waves

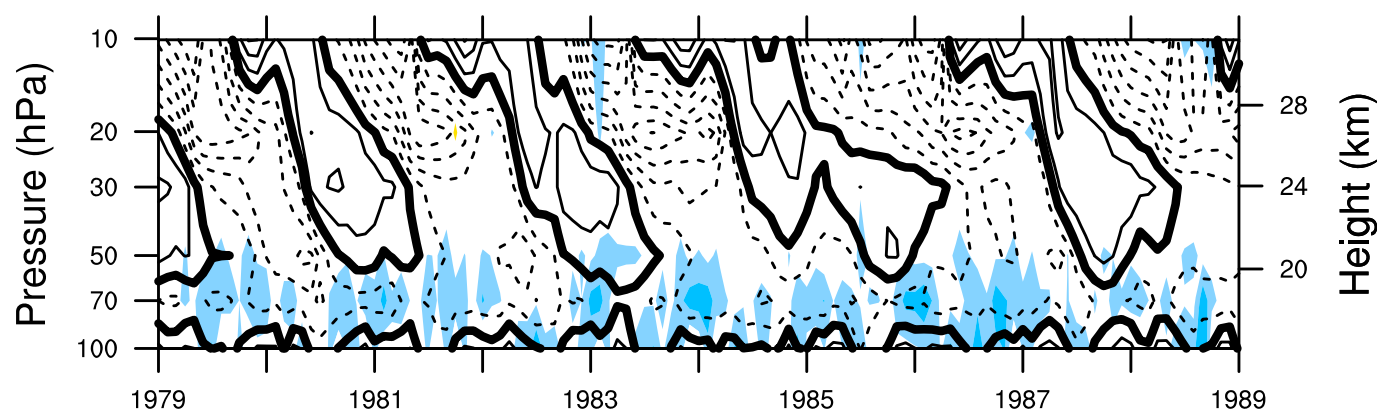

(d) Forcing by parameterized CGWs

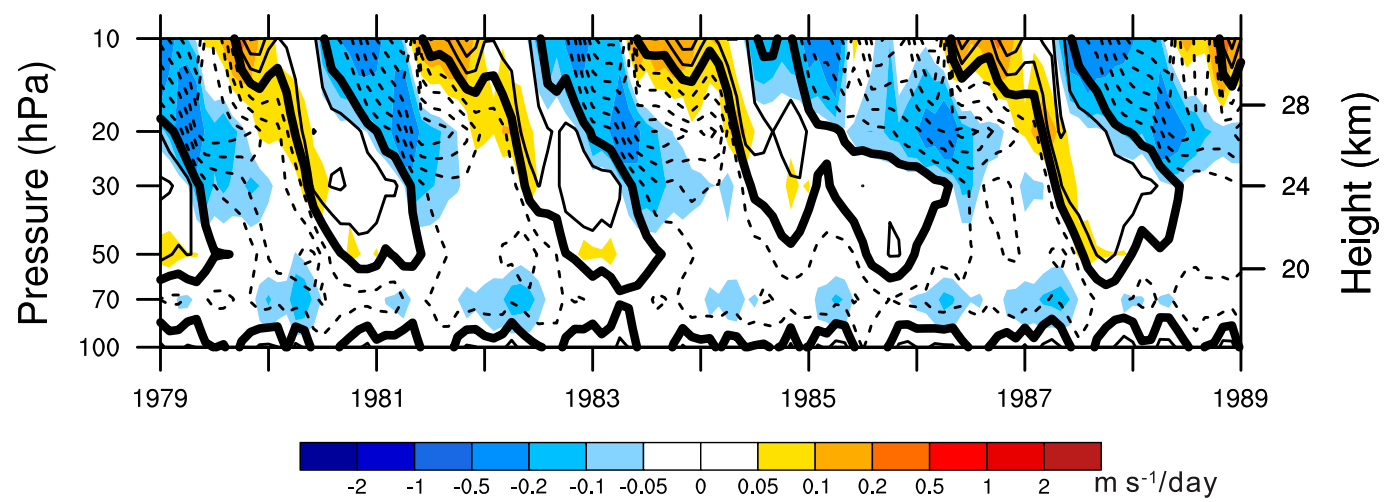

FIG. 13. Time-height cross sections of the wave forcing (shading) from (a) all resolved waves, (b) Kelvin waves, (c) MRG waves, and (d) parameterized convective GWs, superimposed with the zonal wind (contour lines) averaged between $5^{\circ} \mathrm{N}$ and $5^{\circ} \mathrm{S}$ from 1979 to 1988 in L68CGW. Positive (negative) zonal winds are plotted with solid (dashed) lines with a contour interval of $5 \mathrm{~m} \mathrm{~s}^{-1}$. Thick contour line denotes zero zonal wind speed. 
comes primarily from Kelvin waves. Westward forcing is provided largely by parameterized GWs, also contained above $30 \mathrm{hPa}$. Among the resolved waves providing westward forcing, MRG waves barely contribute to the formation of the QBO (Fig. 13c). This finding is similar to that of Kawatani et al. (2010) who found that MRG waves provide only $10 \%$ of the easterly QBO forcing.

\section{Summary and conclusions}

This study has investigated the roles of equatorial waves in driving the QBO using a GCM. The model well captured some aspects of the observed QBO variability, such as the period variability, and asymmetry in the amplitude and meridional extent between westerly and easterly phases. This largely results from a great degree of variability in the parameterized GWs, of which the spatiotemporal variations are highly correlated with that of convective sources. Further analysis found that the eastward forcing by Kelvin waves and parameterized GWs are comparable, while parameterized GWs are the main contributor to the westward wind shear of the simulated QBO.

The realistic QBO simulation is a prerequisite for analyzing the forcing mechanism. Conventional view is that a vertical resolution of less than $1 \mathrm{~km}$ is needed to properly simulate the $\mathrm{QBO}$ in a general circulation model. It has been argued that finer vertical layering of at least $500 \mathrm{~m}$ is required for the proper downward extension to tropopause levels as it permits wavemean flow interactions in the upper troposphere-lower stratosphere region to be resolved in the model (Geller et al. 2016). The simulated behavior of GWs also shows a strong dependence on the model's resolution (Watanabe et al. 2015). It is not known that whether a vertical resolution of $\sim 500 \mathrm{~m}$ is adequate to an accurate QBO simulation. In future, more work will be done to simulate a better QBO by using a higher vertical resolution better than $500 \mathrm{~m}$.

The advantage of the Beres scheme used in this study is that it is coupled to the convection scheme and provides a great degree of variability in the GW sources. In a present day climate simulation, a fixed GW source scheme can be tuned to resemble the variable $\mathrm{GW}$ source scheme in the mean QBO properties, however with the variable source scheme a connection between strong El Niño events and the QBO should be found, and the simulations of the QBO will diverge in a warmer climate (Schirber et al. 2015). The effect of the difference between fixed and variable GW sources on the QBO is outside the scope of the paper and will be explored in detail in future work. The source momentum fluxes show a strong dependence on properties of the convection scheme. It should be noted that the deficiencies in the convection scheme also affect the parameterized GWs. On the other hand, accurate representation of large-scale equatorial waves, including Kelvin waves and MRG waves is sensitive to convection parameterizations. Therefore, the improvement of the convection scheme is crucial to proper representation of the QBO in GCMs. This is a challenge given that improving AGCM representation of convection and clouds is one of the major uncertainties in current climate models.

While the diabatic heating in convection has been considered as a source of waves in convective GW parameterizations, several numerical studies also have demonstrated the importance of nonlinear forcing in the convective GW generation mechanism (Chun et al. 2008; Kang et al. 2018). Both forcing mechanisms should be considered in the convective GW parameterization. Sensitivity studies of the simulated QBO to different GW parameterizations will be carried out in future work.

Acknowledgments. This work was supported by the National Key Research and Development Program of China (2016YFA0602100) and the Welfare Program of Meteorology (GYHY201506011). Adam Scaife and Martin Andrews were supported by the U.K.-China Research and Innovation Partnership Fund through the Met Office Climate Science for Service Partnership (CSSP) China as part of the Newton Fund. Portions of this study were supported by the Regional and Global Model Analysis (RGMA) component of the Earth and Environmental System Modeling Program of the U.S. Department of Energy's Office of Biological \& Environmental Research (BER) via National Science Foundation IA 1947282. The ERA-Interim data are available at https://www.ecmwf.int/en/research/climatereanalysis/era-interim. The authors thank the three anonymous reviewers for their valuable comments that helped to improve the manuscript.

\section{REFERENCES}

Andrews, D. G., J. R. Holton, and C. B. Leovy, 1987: Middle Atmosphere Dynamics. Academic Press, 489 pp.

Andrews, M. B., J. R. Knight, A. A. Scaife, Y. Lu, T. Wu, L. J. Gray, and V. Schenzinger, 2019: Observed and simulated teleconnections between the stratospheric quasi-biennial oscillation and Northern Hemisphere winter atmospheric circulation. J. Geophys. Res. Atmos., 124, 1219-1232, https:// doi.org/10.1029/2018JD029368.

Anstey, J. A., and T. G. Shepherd, 2014: High-latitude influence of the quasi-biennial oscillation. Quart. J. Roy. Meteor. Soc., 140, 1-21, https://doi.org/10.1002/qj.2132.

, J. F. Scinocca, and M. Keller, 2016: Simulating the QBO in an atmospheric general circulation model: Sensitivity to resolved 
and parameterized forcing. J. Atmos. Sci., 73, 1649-1665, https://doi.org/10.1175/JAS-D-15-0099.1.

Baldwin, M. P., and Coauthors, 2001: The quasi-biennial oscillation. Rev. Geophys., 39, 179-229, https://doi.org/10.1029/ 1999RG000073.

Beres, J. H., M. J. Alexander, and J. R. Holton, 2004: A method of specifying the gravity wave spectrum above convection based on latent heating properties and background wind. J. Atmos. Sci., 61, 324-337, https://doi.org/10.1175/1520-0469(2004)061<0324: AMOSTG $>2.0 . \mathrm{CO} ; 2$.

Boer, G., and K. Hamilton, 2008: QBO influence on extratropical predictive skill. Climate Dyn., 31, 987-1000, https://doi.org/ 10.1007/s00382-008-0379-5.

Butchart, N., and Coauthors, 2018: Overview of experiment design and comparison of models participating in phase 1 of the SPARC Quasi-Biennial Oscillation initiative (QBOi). Geosci. Model Dev., 11, 1009-1032, https://doi.org/10.5194/gmd-11-1009-2018.

Camargo, S. J., and A. H. Sobel, 2010: Revisiting the influence of the quasi-biennial oscillation on tropical cyclone activity. J. Climate, 23, 5810-5825, https://doi.org/10.1175/2010JCLI3575.1.

Chen, W., and T. Li, 2007: Modulation of northern hemisphere wintertime stationary planetary wave activity: East Asian climate relationships by the Quasi-Biennial Oscillation. J. Geophys. Res., 112, D20120, https://doi.org/10.1029/2007JD008611.

Chun, H.-Y., H.-J. Choi, and I.-S. Song, 2008: Effects of nonlinearity on convectively forced internal gravity waves: Application to a gravity wave drag parameterization. J. Atmos. Sci., 65, 557-575, https://doi.org/10.1175/2007JAS2255.1.

Dee, D. P., and Coauthors, 2011: The ERA-Interim reanalysis: Configuration and performance of the data assimilation system. Quart. J. Roy. Meteor. Soc., 137, 553-597, https://doi.org/ 10.1002/qj.828.

Dunkerton, T. J., 1997: The role of gravity waves in the quasibiennial oscillation. J. Geophys. Res., 102, 26053-26076, https://doi.org/10.1029/96JD02999.

Fadnavis, S., P. E. Raj, P. Buchunde, and B. N. Goswami, 2014: In search of influence of stratospheric quasi-biennial oscillation on tropical cyclones tracks over the Bay of Bengal region. Int. J. Climatol., 34, 567-580, https://doi.org/10.1002/joc.3706.

Geller, M. A., and Coauthors, 2016: Modeling the QBO - Improvements resulting from higher-model vertical resolution. J. Adv. Model. Earth Syst., 8, 1092-1105, https://doi.org/ 10.1002/2016MS000699.

Giorgetta, M. A., E. Manzini, and E. Roeckner, 2002: Forcing of the quasi-biennial oscillation from a broad spectrum of atmospheric waves. Geophys. Res. Lett., 29, 1245, https://doi.org/ 10.1029/2002GL014756.

M. Esch, and L. Bengtsson, 2006: Climatology and forcing of the quasi-biennial oscillation in the MAECHAM5 model. J. Climate, 19, 3882-3901, https://doi.org/10.1175/ JCLI3830.1.

Ho, C.-H., H.-S. Kim, J.-H. Jeong, and S.-W. Son, 2009: Influence of stratospheric quasi-biennial oscillation on tropical cyclone tracks in the western North Pacific. Geophys. Res. Lett., 36, L06702, https://doi.org/10.1029/2009GL037163.

Holton, J. R., and R. S. Lindzen, 1972: An updated theory for the quasi-biennial cycle of the tropical stratosphere. J. Atmos. Sci., 29, 1076-1080, https://doi.org/10.1175/1520-0469(1972)029<1076: AUTFTQ $>2.0 . \mathrm{CO} ; 2$

, and H.-C. Tan, 1980: The influence of the equatorial quasibiennial oscillation on the global circulation at $50 \mathrm{mb}$. J. Atmos. Sci., 37, 2200-2208, https://doi.org/10.1175/1520-0469(1980) 037<2200:TIOTEQ>2.0.CO;2.
— and - 1982: The quasi-biennial oscillation in the northern hemisphere lower stratosphere. J. Meteor. Soc. Japan, 60, 140148, https://doi.org/10.2151/jmsj1965.60.1_140.

Inoue, M., and M. Takahashi, 2013: Connections between the stratospheric quasi-biennial oscillation and tropospheric circulation over Asia in northern autumn. J. Geophys. Res. Atmos., 118, 10 740-10 753, https://doi.org/10.1002/JGRD.50827.

Kang, M.-J., H.-Y. Chun, Y.-H. Kim, P. Preusse, and M. Ern, 2018: Momentum flux of convective gravity waves derived from an offline gravity wave parameterization. Part II: Impacts on the quasi-biennial oscillation. J. Atmos. Sci., 75, 3753-3775, https://doi.org/10.1175/JAS-D-18-0094.1.

Kawatani, Y., K. Tsuji, and M. Takahashi, 2005: Zonally nonuniform distribution of equatorial gravity waves in an atmospheric general circulation model. Geophys. Res. Lett., 32, L23815, https://doi.org/10.1029/2005GL024068.

—, M. Takahashi, K. Sato, S. P. Alexander, and T. Tsuda, 2009: Global distribution of atmospheric waves in the equatorial upper troposphere and lower stratosphere: AGCM simulation of sources and propagation. J. Geophys. Res., 114, D01102, https://doi.org/10.1029/2008JD010374.

—, K. Sato, T. J. Dunkerton, S. Watanabe, S. Miyahara, and M. Takahashi, 2010: The roles of equatorial trapped waves and internal inertia-gravity waves in driving the quasi-biennial oscillation. Part I: Zonal mean wave forcing. J. Atmos. Sci., 67, 963-980, https://doi.org/10.1175/2009JAS3222.1.

Kiladis, G. N., M. C. Wheeler, P. T. Haertel, K. H. Straub, and P. E. Roundy, 2009: Convectively coupled equatorial waves. Rev. Geophys., 47, RG2003, https://doi.org/10.1029/ 2008RG000266.

Kim, Y. H., and H. Y. Chun, 2015: Momentum forcing of the quasibiennial oscillation by equatorial waves in recent reanalyses. Atmos. Chem. Phys., 15, 6577-6587, https://doi.org/10.5194/ acp-15-6577-2015.

—- A. C. Bushell, D. R. Jackson, and H.-Y. Chun, 2013: Impacts of introducing a convective gravity-wave parameterization upon the QBO in the Met Office Unified Model. Geophys. Res. Lett., 40, 1873-1877, https://doi.org/10.1002/ grl.50353.

Liebmann, B., and C. A. Smith, 1996: Description of a complete (interpolated) outgoing longwave radiation dataset. Bull. Amer. Meteor. Soc., 77, 1275-1277, https://doi.org/10.1175/ 1520-0477-77.6.1274.

Lindzen, R. S., 1981: Turbulence and stress owing to gravity wave and tidal breakdown. J. Geophys. Res., 86, 9707-9714, https:// doi.org/10.1029/JC086iC10p09707.

— , and J. R. Holton, 1968: A theory of the quasi-biennial oscillation. J. Atmos. Sci., 25, 1095-1107, https://doi.org/10.1175/ 1520-0469(1968)025<1095:ATOTQB > 2.0.CO;2.

Lott, F., and L. Guez, 2013: A stochastic parameterization of the gravity waves due to convection and its impact on the equatorial stratosphere. J. Geophys. Res. Atmos., 118, 8897-8909, https://doi.org/10.1002/JGRD.50705.

Marshall, A. G., H. H. Hendon, S.-W. Son, and Y. Lim, 2017: Impact of the quasi-biennial oscillation on predictability of the Madden-Julian oscillation. Climate Dyn., 49, 1365-1377, https://doi.org/10.1007/s00382-016-3392-0.

McFarlane, N. A., 1987: The effect of orographically excited wave drag on the general circulation of the lower stratosphere and troposphere. J. Atmos. Sci., 44, 1775-1800, https://doi.org/ 10.1175/1520-0469(1987)044<1775:TEOOEG >2.0.CO;2.

Naujokat, B., 1986: An update of the observed quasi-biennial oscillation of the stratospheric winds over the tropics. J. Atmos. Sci., $\mathbf{4 3}$ 
1873-1877, https://doi.org/10.1175/1520-0469(1986)043<1873: AUOTOQ $>2.0 . \mathrm{CO} ; 2$.

Nishimoto, E., and S. Yoden, 2017: Influence of the stratospheric quasi-biennial oscillation on the Madden-Julian oscillation during austral summer. J. Atmos. Sci., 74, 1105-1125, https:// doi.org/10.1175/JAS-D-16-0205.1.

Richter, J. H., F. Sassi, and R. R. Garcia, 2010: Toward a physically based gravity wave source parameterization in a general circulation model. J. Atmos. Sci., 67, 136-156, https://doi.org/ 10.1175/2009JAS3112.1.

— A. Solomon, and J. T. Bacmeister, 2014: On the simulation of the quasi-biennial oscillation in the Community Atmosphere Model, version 5. J. Geophys. Res. Atmos., 119, 3045-3062, https://doi.org/10.1002/2013JD021122.

Rind, D., J. Jonas, N. K. Balachandran, G. A. Schmidt, and J. Lean, 2014: The QBO in two GISS global climate models: 1. Generation of the QBO. J. Geophys. Res. Atmos., 119, 8798-8824, https://doi.org/10.1002/2014JD021678.

Scaife, A. A., and Coauthors, 2014: Predictability of the quasibiennial oscillation and its northern winter teleconnection on seasonal to decadal timescales. Geophys. Res. Lett., 41, 17521758, https://doi.org/10.1002/2013GL059160.

_ , N. Butchart, C. D. Warner, D. Stainforth, W. Norton, and J. Austin, 2000: Realistic quasi-biennial oscillations in a simulation of the global climate. Geophys. Res. Lett., 27, 34813484, https://doi.org/10.1029/2000GL011625.

,,--- , and R. Swinbank, 2002: Impact of a spectral gravity wave parameterization on the stratosphere in the Met Office Unified Model. J. Atmos. Sci., 59, 1473-1489, https://doi.org/ 10.1175/1520-0469(2002)059<1473:IOASGW>2.0.CO;2.

Schenzinger, V., S. Osprey, L. Gray, and N. Butchart, 2017: Defining metrics of the quasi-biennial oscillation in global climate models. Geosci. Model Dev., 10, 2157-2168, https://doi.org/ 10.5194/gmd-10-2157-2017.

Schirber, S., E. Manzini, and M. J. Alexander, 2014: A convectionbased gravity wave parameterization in a general circulation model: Implementation and improvements on the QBO. J. Adv. Model. Earth Syst., 6, 264-279, https://doi.org/10.1002/ 2013MS000286.

,$- \ldots$, T. Krismer, and M. Giorgetta, 2015: The quasi-biennial oscillation in a warmer climate: Sensitivity to different gravity wave parameterizations. Climate Dyn., 45, 825-836, https:// doi.org/10.1007/s00382-014-2314-2.

Son, S.-W., Y. Lim, C. Yoo, and H. H. Hendon, 2017: Stratospheric control of the Madden-Julian oscillation. J. Climate, 30, 19091922, https://doi.org/10.1175/JCLI-D-16-0620.1.

Takahashi, M., 1996: Simulation of the stratospheric quasi-biennial oscillation using a general circulation model. Geophys. Res. Lett., 23, 661-664, https://doi.org/10.1029/95GL03413.

_ 1999: Simulation of the quasi-biennial oscillation in a general circulation model. Geophys. Res. Lett., 26, 1307-1310, https:// doi.org/10.1029/1999GL900188.
_ and B. A. Boville, 1992: A three-dimensional simulation of the equatorial quasi-biennial oscillation. J. Atmos. Sci., 49, 1020-1035, https://doi.org/10.1175/1520-0469(1992)049<1020: ATDSOT $>2.0 . \mathrm{CO} ; 2$.

Thompson, D. W. J., M. P. Baldwin, and J. M. Wallace, 2002: Stratospheric connection to Northern Hemisphere wintertime weather: Implications for prediction. J. Climate, 15, 1421-1428, https://doi.org/10.1175/1520-0442(2002)015<1421: SCTNHW $>2.0 . \mathrm{CO} ; 2$.

Watanabe, S., K. Sato, Y. Kawatani, and M. Takahashi, 2015: Vertical resolution dependence of gravity wave momentum flux simulated by an atmospheric general circulation model. Geosci. Model Dev., 8, 1637-1644, https://doi.org/10.5194/ gmd-8-1637-2015.

Wheeler, M., and G. N. Kiladis, 1999: Convectively coupled equatorial waves: Analysis of clouds and temperature in the wavenumber-frequency domain. J. Atmos. Sci., 56, 374-399, https://doi.org/10.1175/1520-0469(1999)056<0374: $\mathrm{CCEWAO}>2.0 . \mathrm{CO} ; 2$

Wu, T., 2012: A mass-flux cumulus parameterization scheme for large-scale models: Description and test with observations. Climate Dyn., 38, 725-744, https://doi.org/10.1007/ s00382-011-0995-3.

_ - R. Yu, and F. Zhang, 2008: A modified dynamic framework for atmospheric spectral model and its application. J. Atmos. Sci., 65, 2235-2253, https://doi.org/10.1175/ 2007JAS2514.1.

— - and Coauthors, 2010: The Beijing Climate Center atmospheric general circulation model: Description and its performance for the present-day climate. Climate Dyn., 34, 123-147, https:// doi.org/10.1007/s00382-008-0487-2.

_ - and Coauthors, 2014: An overview of BCC climate system model development and application for climate change studies. J. Meteor. Res., 28, 34-56, https://doi.org/10.1007/ S13351-014-3041-7.

— , and Coauthors, 2019: The Beijing Climate Center Climate System Model (BCC-CSM): The main progress from CMIP5 to CMIP6. Geosci. Model Dev., 12, 1573-1600, https://doi.org/ 10.5194/gmd-12-1573-2019.

Xue, X.-H., H.-L. Liu, and X.-K. Dou, 2012: Parameterization of the inertial gravity waves and generation of the quasi-biennial oscillation. J. Geophys. Res., 117, D06103, https://doi.org/ 10.1029/2011JD016778.

Yoo, C., and S.-W. Son, 2016: Modulation of the boreal wintertime Madden-Julian oscillation by the stratospheric quasi-biennial oscillation. Geophys. Res. Lett., 43, 1392-1398, https://doi.org/ 10.1002/2016GL067762.

Yu, C., X. Xue, J. Wu, T. Chen, and H. Li, 2017: Sensitivity of the quasi-biennial oscillation simulated in WACCM to the phase speed spectrum and the settings in an inertial gravity wave parameterization. J. Adv. Model. Earth Syst., 9, 389-403, https://doi.org/10.1002/2016MS000824. 